\title{
A Methodology for Assessing Systems Materials Requirements
}

January 1980

U.S. Department of Energy

Office of Energy Research

Satellite Power System Project Office

Washington, D.C. 20545

\section{DOE/NASA}

SATELLITE POWER SYSTEM

Concept Development

and

Evaluation Program 


\section{DISCLAIMER}

This report was prepared as an account of work sponsored by an agency of the United States Government. Neither the United States Government nor any agency Thereof, nor any of their employees, makes any warranty, express or implied, or assumes any legal liability or responsibility for the accuracy, completeness, or usefulness of any information, apparatus, product, or process disclosed, or represents that its use would not infringe privately owned rights. Reference herein to any specific commercial product, process, or service by trade name, trademark, manufacturer, or otherwise does not necessarily constitute or imply its endorsement, recommendation, or favoring by the United States Government or any agency thereof. The views and opinions of authors expressed herein do not necessarily state or reflect those of the United States Government or any agency thereof. 


\section{DISCLAIMER}

Portions of this document may be illegible in electronic image products. Images are produced from the best available original document. 
DOE/ER-0040.

Dist. Category 95f, 97c

\section{A Methodology for Assessing Systems Materials Requirements}

January 1980

Prepared by:

D.H. Culver, R.R. Teeter, W.M. Jamieson

Battelle Columbus Laboratories

505 King Avenue

Columbus, Ohio 43201

Prepared for:

U.S. Department of Energy

Office of Energy Research

Satellite Power System Project Office

Washington, D.C. 20545

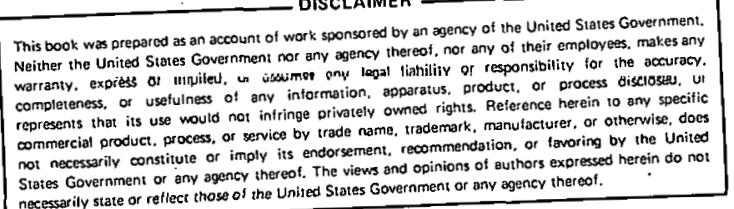

States Government or any agency thereed. The views ond opment or nay ageney thereot.

\section{DOE/NASA}

SATELLITE POWER SYSTEM

Concept Development

and

Evaluation Program 
Avallable from:

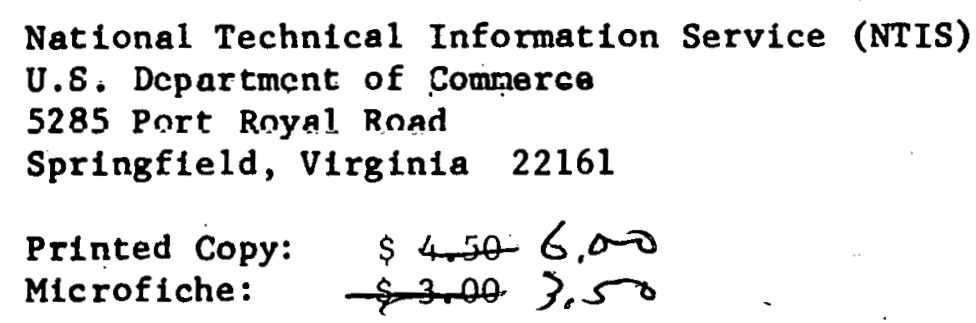


ACKNOWLEDGEMENTS

The authors would like to express their appreciation to several individuals who agreed to review and critique this report. Their comments represented a valuable contribution to the final product. They are:

Paul Brown -- United Engineers

Dr. Meredith Crist.-- University of Southern California

Hal Goeller -- Oak Ridge National Laboratory

Allan Kotin -- Economic consultants

Andrew Prokopovitsh -- U. S. Bureau of Mines 


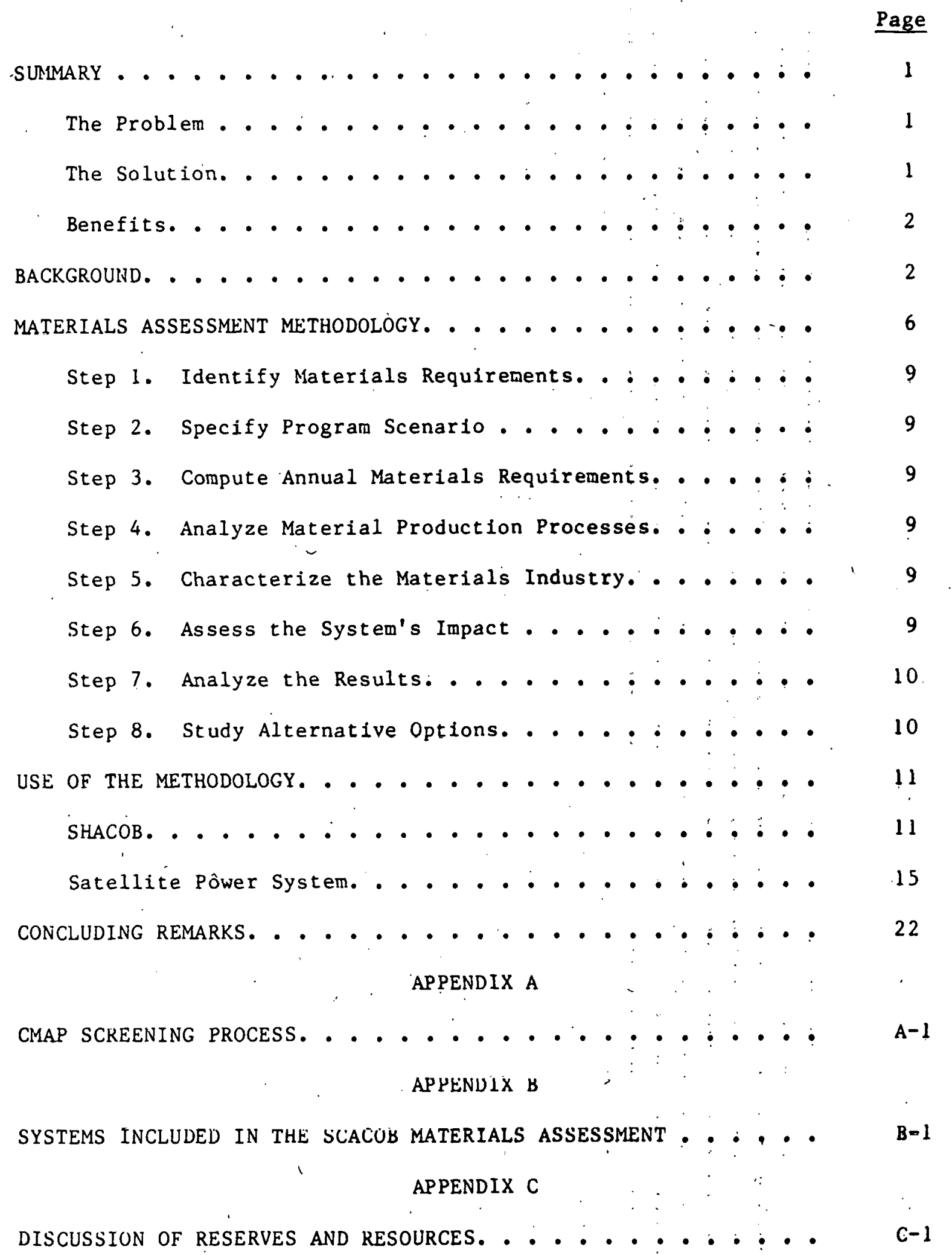


APPENDIX D

BULK AND RAW MATERIALS REQUIREMENTS FOR THE

GaAs 295-GIGAWATT SPS . . . . . . . . . . . . . . .

\section{LIST OF FIGURES}

Figure 1. Policy Level Requirements. . . . . . . . . 3

Figure 2. Planning and Evaluation Requirements . . . . . . 4

Figure 3. Engineering and Design Requirements. . ....... 4

Figure 4. The Haterialc Cyclc. . . . . . . . . . . 6

Figure 5. Typical Conversion Chain or Matrix ....... . 7

Figure 6. Overiview of the Methodology. . . . . . . . 8

Figure 7. Solar Power Satellite............. 16

Figure 8. Constituents of Graphite Fiber and Polysulfone . . 19

Figure 9. Graphite Fiber Production. . . . . . . . . 20

\section{LIST OF TABLES}

Table 1. SHACOB Bulk Materials Requirements. . . . . . . 12

Table 2. SHACOB Raw Materials Requirements . . . . . . 13

Table 3. Bulk Materials Requirements --
295-Gigawatt Silicon SPS. ............ 17

Tablc 4. Raw Materials Reyulrements $==$
295-Gigawatt Silicon SPS. . . . . . . . 18

Tahle 5. Constituent Materials for Pan Fiber. and Polysulfone .............. 19 
A METHODOLOGY FOR ASSESSING

SYSTEMS MATERIALS REQUIREMENTS

SUMMARY

A potential stumbling block to new system planning and design is imprecise, confusing, or contradictory data regarding materials--their availability and costs. A methodology is now available that removes this barrier by minimizing uncertainties regarding materials availability. Using this methodology, a planner can assess materials requirements more quickly, at lower cost, and with much greater confidence in the results. Developed specifically for energy systems, its potential application is much broader.

\section{The Problem}

Major new systems can require vast quantities of materials. Technologically advanced systems may require more--sometimes much more--of certain materials than the world's total current output. Ma.jor expansions of manufacturing capacity, even entire new industries, may be needed to meet these new material requi rements. Other materials--related factors may also have to receive careful attention before a system design is finalized. For example, the extent to which supply is dependent on imports, particularly from one or two uncertain sources, can be critical. Another vital factor may be the effect that a system's impact on demand has on world markets. The costs of large quantities of scarce materials is a third example. There are more.

Policy makers, planners and evaluators, and design engineers must deal with these materials uncertainties. They must assess the requirements of a specific system and also compare the requirements of competing systems or competing technologies within a system. And, they must be able to determine the cumulative effects of developing two or more new systems in parallel.

These efforts have been hampered by the lack of an established, accepted, comparative methodology that can deal with the broad scope of materials uncertainities. Often, well-intentioned planners have been unable to resolve honest disagreements that can arise simply because their analyses are not based on identical data. Communications breakdowns occur and polarization can result.

\section{The Solution}

Under the, direction and funding of DOE's Satellite Power System's Projcct office, a methodology has been developed that solves many of these problems. At its heart is an automated data base containing 
Information on the raw and bulk materials (including energy consumption) from which new systems, as well as their components and subsystems, are manufactured. The methodology includes data and algorithms that tell planners and designers such things as how much expansion in capacity will be needed to produce the projected quantities of each material, how much of the material comes from abroad, and its cost per unit of system output. Materials that exceed certain threshold values are: flagged to help assure that they will be studied more closely.

The methodology has been tested and successfully applied to four proposed future energy production systems. $(1-4)$ It is now ready for wider use.

\section{Benefits}

A principal benefit of the methodology is the ease of performing "whatit" analyses. Planners, managers, and designers can all quickly determine the effects of, say, substituting one material for another, one component for another, or one subsystem for another. Because such, analyses become relatively easy, there should be less reluctance to undertake them. This factor alone can ensure more efficient, less costly sys tems:

Use of the methodology will also:

$r$

- Provide a better basis for decision-making

- Minimize uncertainties regarding materials availability

- Provide lear time if R\&D or major expensions of capacily prove necessary

- Gulde decisions as to the ultimate size and timing of new systems

- Raise the success probability of new systems ventures

- Save timc and muney liy makling avallable a comprehensive materials data base coupled to an automated data processing system.

\section{BACKGROUND}

Major new energy systems being studied to replace or supplenent fossilfuel systems will have significant impacts on the life of our nation and on many aspects of our personal lives. Some of these systems require huge amounts of increasingly scarce land. Most of them require heavy capital investments. In many cases, international agreements may be necessary, often with military implications. 
As a result of these potential impacts, there are many factors that require careful attention in considering new systems. Societal impacts, economic effects, and environmental concerns must be weighed, together with the issue of public acceptance. Governmental regulations, building codes, and other institutional factors also require close scrutiny. Of major importance among these many concerns is consideration of materials requirements. Vast quantities of materials can be needed--some of them rare, others costly, many already in heavy demand. For example, one version of the proposed 300-gigawat* Satellite Power System (SPS) will require almost 900 million metric tons of bulk materials** (ranging from the common, such as sand and gravel, to the rare or exotic, such as gallium arsenide).

During system development, the implications of materials requirements for energy systems are considered at three levels--each with a different perspective. Planners at the policy level, for example, focus on either the cumulative materials requirements of several types of systems, such as solar, nuclear, and fossil fuel, or on decisions involving comparisons among competing systems, the "either/or" situation (Figure 1).

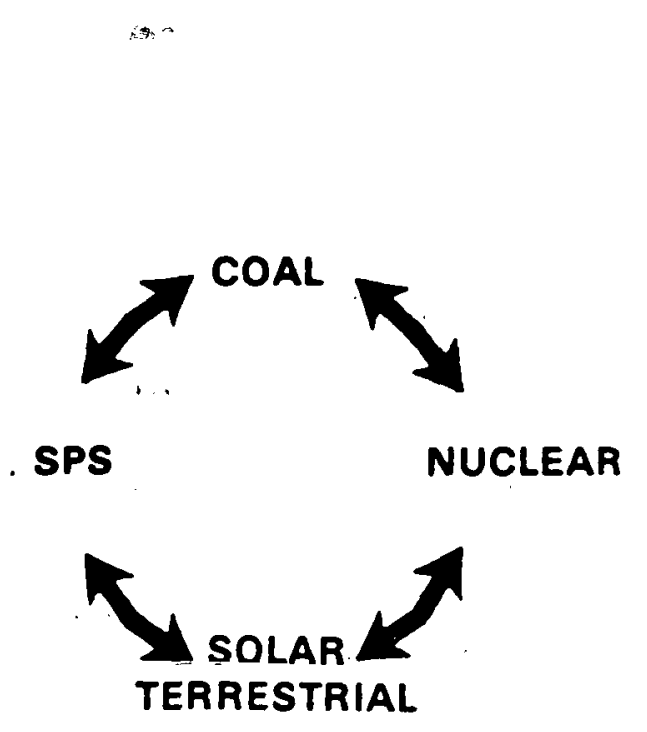

TRADE-OFFS /COMPARISONS

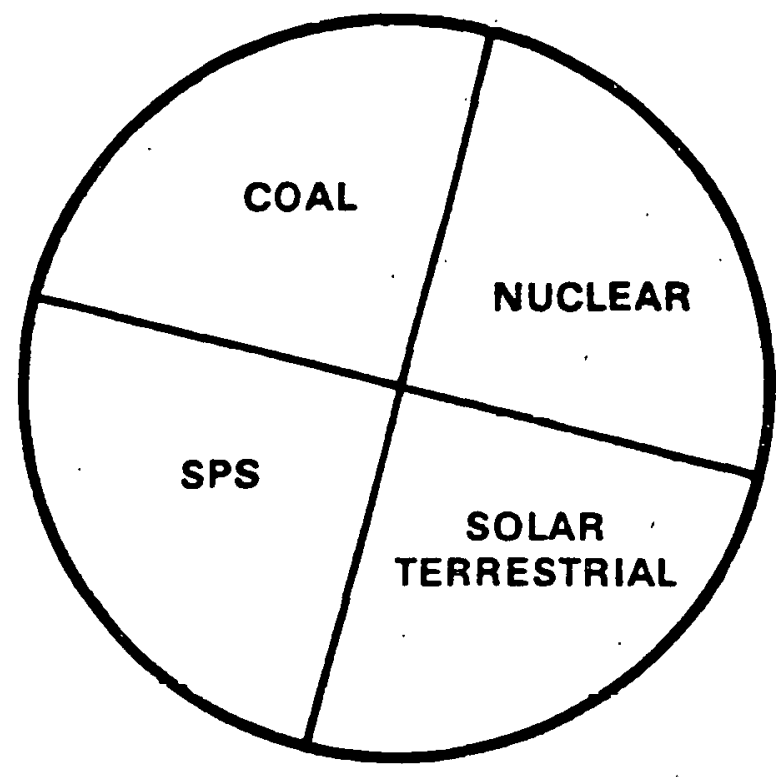

CUMULATIVE

FIGURE 1. POLICY LEVEL REQUIREMENTS

*60 five-gigawatt satellites

**An analogy can be drawn from the automobile industry: 900 million metric tons of bulk materials is equivalent to the cumulative output of the entire U.S. automobile industry (at 10,000,000 cars per year) for over 60 years! 
At the planning and evaluation level (Figure 2), managers analyze intrasystem requirements. Examples might be materials needed by a siliconbased SPS versus one using gallium arsenide technology, or active versus passive solar terrestrial systems. 'As analyses have already shown, there can be very significant differences in materials requirements even between relatively similar systems.

- INTRASYSTEM COMPARISONS

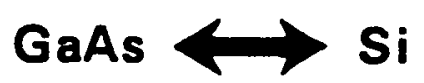

- PROGRAM SCENARIO VARIATIONS

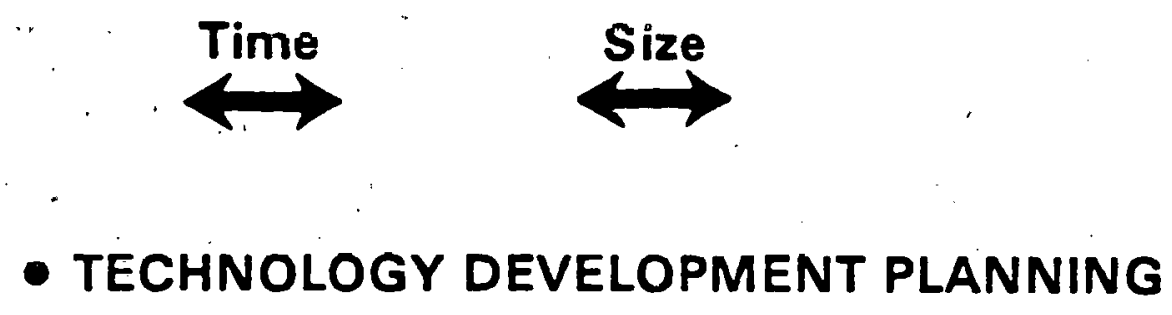

FIGURE 2. PLANNING AND EVALUATION REQUIREMENTS

Finally, engineering designers perform trade-off analyses to optimize a system's design (Figure 3). Matcrials wust be evaluated along with other factors such as technical characteristics (e.g., strength, availability, cost, and welght) before a design can be finalized.

\section{STRUCTURAL MATERIALS EXAMPLE}
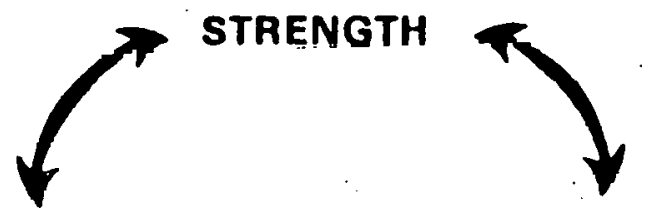

WEIGHT

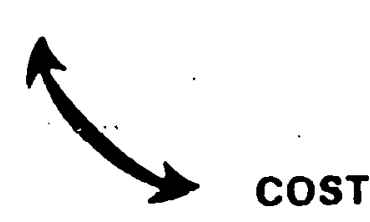

AVAILABILITY

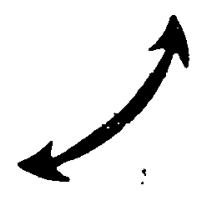

FIGURE 3. ENGINEERING AND DESIGN REQUIREMENTS 
There are several factors that can affect the choice of materials, in addition to normal engineering design considerations. These include:

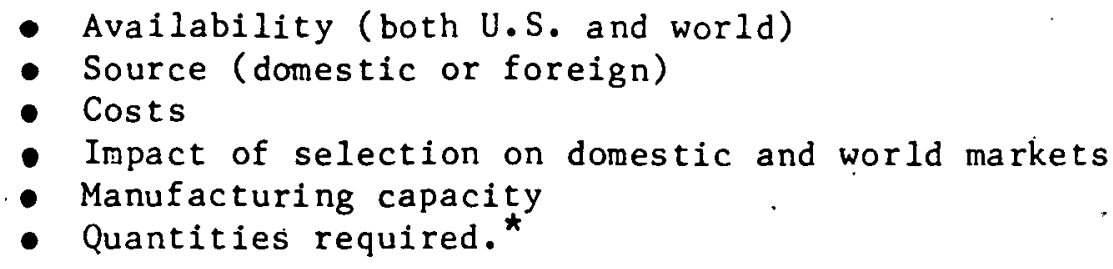

Other factors must also be carefully studied--environmental impacts, capital requirements, energy payback, balance of trade impacts, and $R \& D$ requi rements. Analyses to date have shown that there are many materials whose use would pose no concern, even though a new system may require large quantities. Other materials (as many as 50 percent) may raise some concern as regards one or more of the factors mentioned above. These materials require further analysis. Typically, such analyses reveal that most of these materials pose no serious concern. This leaves, then, those few materials whose use may have significant impacts. The problem then is not with the number of materials of concern but with identifying those few materials of concern. A systematic approach is needed to do this in an efficient manner.

Although the needs for materials data range from the very broad to the very specific, there is a. common requi rement for an established, accepted, comparative methodology that can simplify and speed up the laborious and expensive process of comprehensive materials assessments.

In 1976, DOE's Satellite Power System's Project Office contracted with Battelle Memorial Institute to develop such a methodology. (1) It now exists. It has been tested with four energy systems--terrestrial solar photovoltaics(2), solar heating and cooling of buildings(3), solar agricultural and industrial process heat $(3)$, and the Satellite Power system. (4)

This methodology provides a valuable new tool. While by no means eliminating the need for the mature judgment of experienced managers and designers, it largely frees them from the grinding, costly manipulation of huge quantities of data. And, it meets the needs of all three levels mentioned above--policy makers, planners, and designers--in a single sys tem.

By applying this methodology, comparative and accumulative assessments can be performed with relative ease, and future developmental and commercial impacts of materials requi rements can be addressed. Its use will help reduce the uncertainties presently surrounding materials

*As determined by the system's scenario (output/size of units and number of units per year). 
requirements of major systems and allow quick comparison of design alternatives'. It should also help prevent missteps that could have farreaching ramifications.

In the remainder of this report, we describe the methodology and present illustrations of its application.

\section{MATERIALS ASSESSMENT METHODOLOGY (1)}

One usually thinks of the flow of materials proceeding from raw materials to the tinal materials (Figure 4). Take for example, copper. Copper ore is mined and sent to a mill and smelter. The bulk material, copper, that leaves this process may be formed into a final engineering material like brass (an alloy of copper and zinc). This brass may then be machined and fabricated into hardware components for the SPS or some other system. The tracking process needed in a materials assessment follows the opposite direction. First, the amount of brass in the system being studied must be determined. Then this is translated into its bulk materials, one of which is copper. At this point the bulk material copper would be reviewed for possible capacity constraints. Next the copper production process would be analyzed and its material needs identified: copper ore, sulfuric acid, steel, electricity, coal,

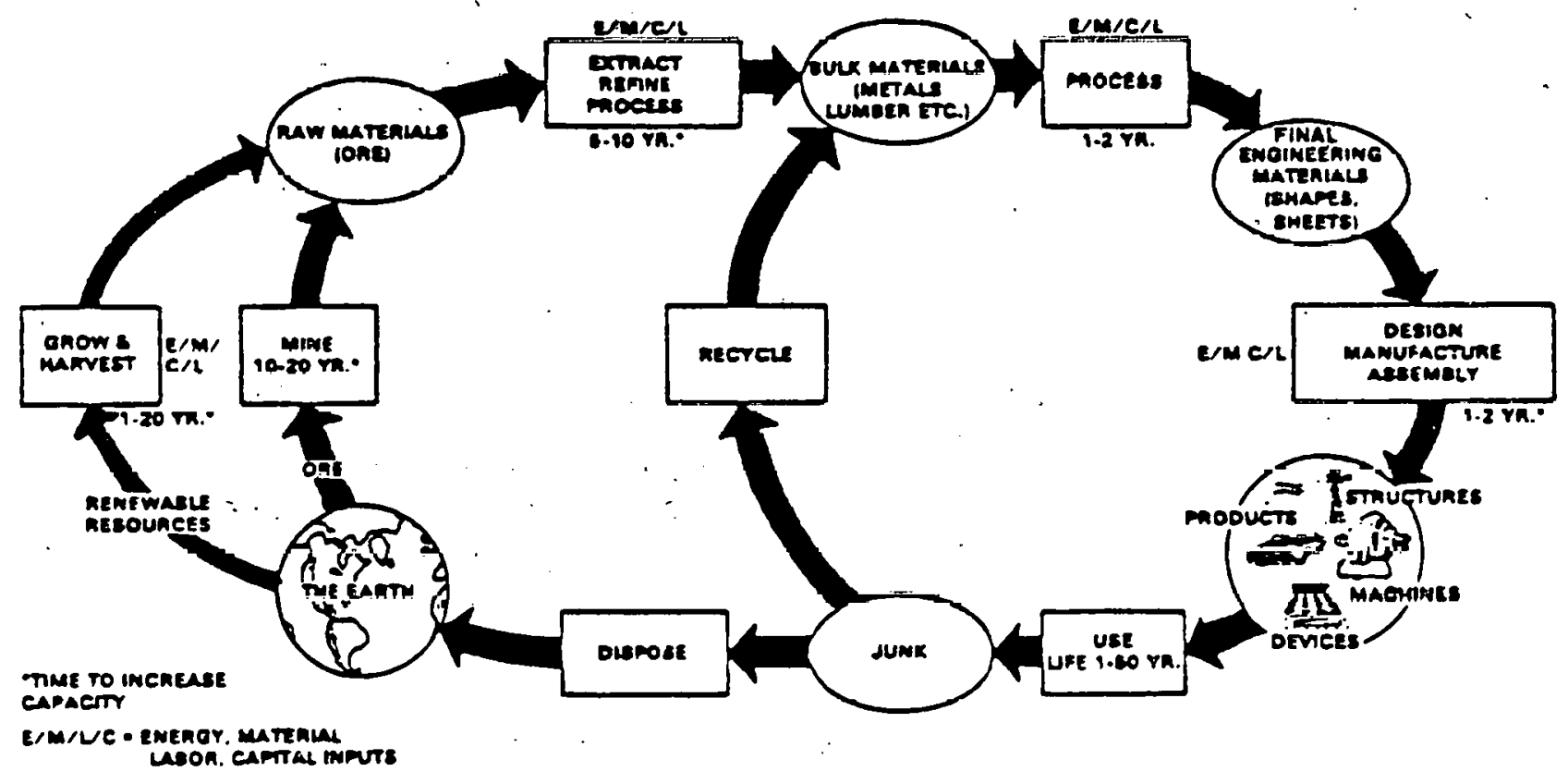

FIGURE 4. THE MATERIALS CYCLE

(1) 
etc. The copper ore and all of the other bulk* and raw materials are then checked for potential capacity constraints and for avallability of reserves and resources. Figure 5 describes the foregoing relationships graphically. The production processes of the secondary materials must also be analyzed to complete the materials assessment. This analysis logic could conceivably proceed on through several additional steps but in practice is terminated when material quantities become insignificant.

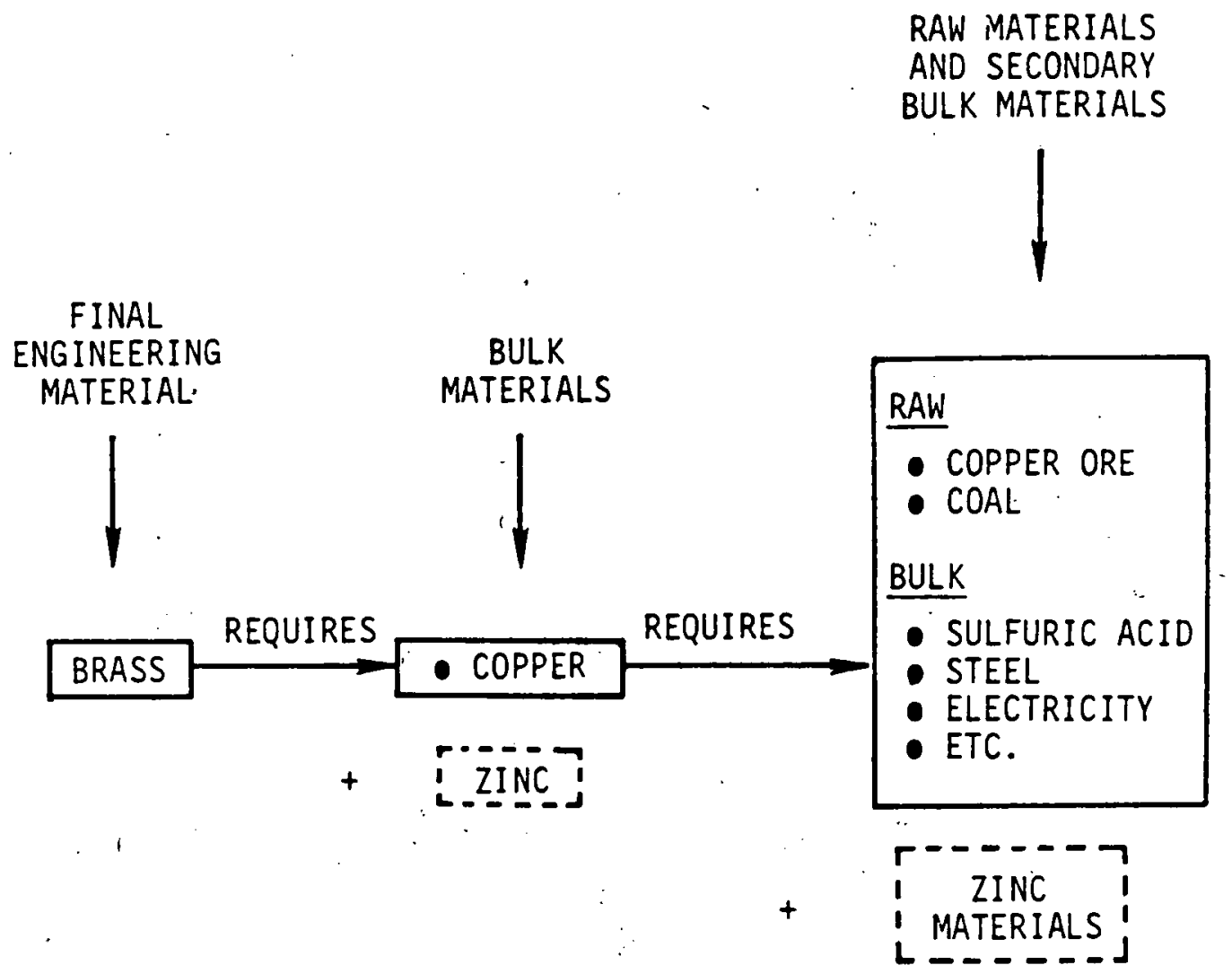

FIGURE 5. TYPICAL CONVERSION CHAIN OR MATRIX

When the above simplified example is expanded to a overall. materials assessment of a total system (such as the Satellite Power System), the problem becomes much more complex, involving large numbers of materials and production processes. The analysis required can best be described as consisting of the following eight basic steps (refer also to Figure 6):

* Bulk materials requi red to produce other bulk materials (e.g. sulfuric acid required to produce copper) are referred to as "secondary" bulk materials. 


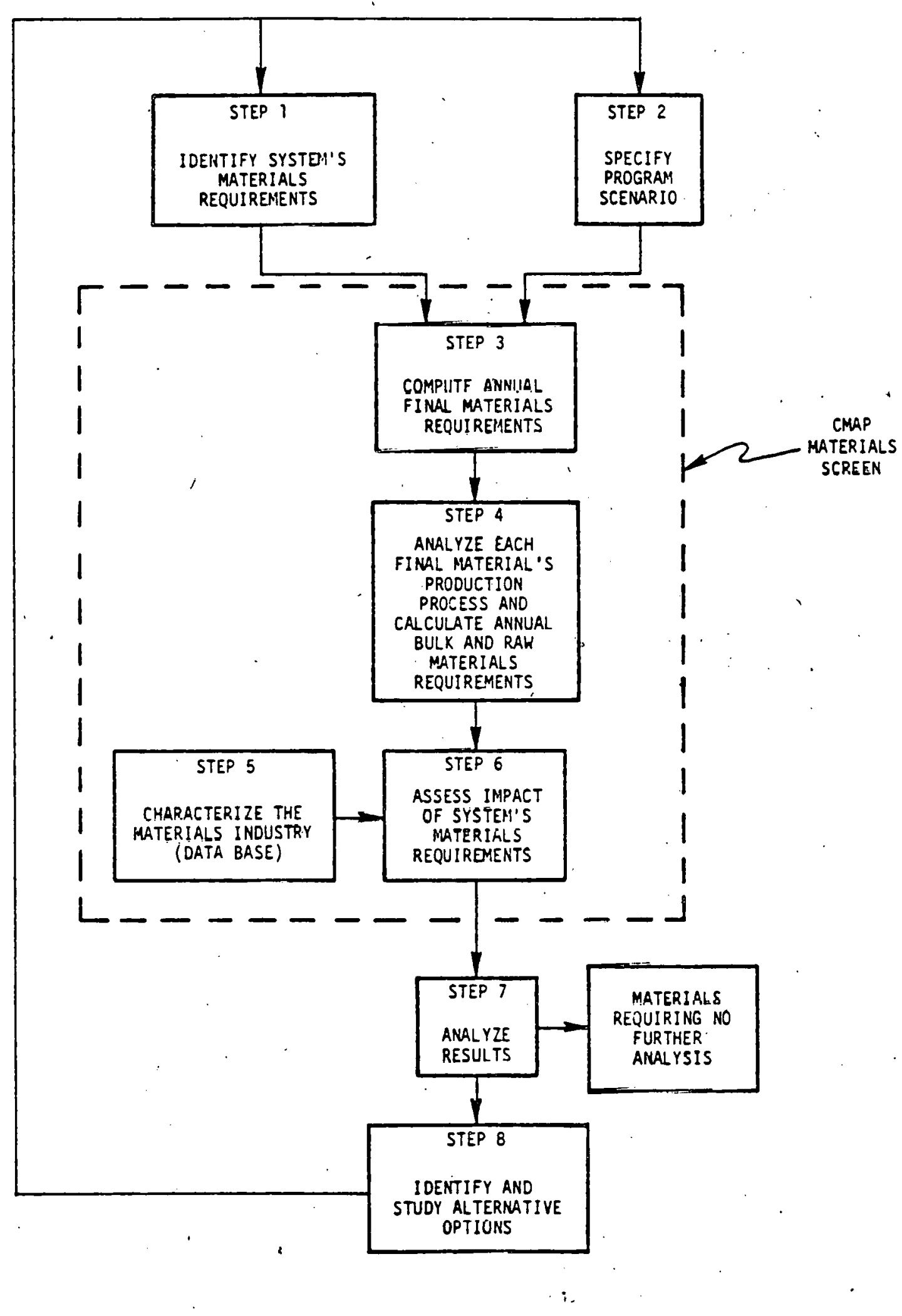

FIGURE 6. OVERVIEW OF THE METHODOLOGY 


\section{Step 1. Identify Materials Requirements}

The final construction materials (such as brass, concrete, composites, or solar-grade silicon) for a system under study are identified, preferably at the component or subsystem level. This results in a listing of the quantities of all materials required for the construction and installation of one system "unit" (such as one solar power satellite and its earthborn equipment, or one coal-fired generating plant) producing a specified amount of energy.

\section{Step 2. Specify Program Scenario}

A "scenario" is a statement of a system's ultimate size and the timing of its construction. The scenario gives the number of system units to be constructed per year for each year of the program's duration. The SPS scenario, for example, specifies two satellite units per year throughout the period from 2000 to 2029 , for a total of 60 units each developing 5 gigawatts output. Thus the total power output at program completion would be 300 gigawats.

\section{Step 3. Compute Annual Materials Requirements}

The annual materials requirements are calculated by multiplying the units per year by the quantities of each final material in one unit.

\section{Step 4. Analyze Materlal Production Processes}

Each final construction material is produced from bulk and secondary bulk materials. (such as copper, cement, graphite fiber, or sulfuric acid) and raw materials (such as sand and gravel, ore, or timber). Quantities of all such materials are calculated by year.

\section{Step 5. Characterize the Materials Industry}

For all materials, a data base is developed. It includes such factors as availability, source, production capacity, expected growth in demand, and prices on a domestic and worldwide basis for each material..

\section{Step 6. Assess the System's Impact}

The system's annual demand for each material (as determined in SLeps 14 ) is compared to pertinent information in the data base for that material. This reveals the impacts of the system, expressed in such terms as percentage of total production required, percentage of resources consumed, or dependency on imports. 


\section{Step 7. Analyze the Results}

The significance of each impact identified in Step 6 is assessed by comparison to a predetermined threshold value. Some impacts will be of no concern; others will require further study.

\section{Step 8. Study Alternative Options}

For those materials involving significant uncertainties, or potential constraints, alternative options are identified and studied. One option is materials substitutions. If this is considered, Steps 1 through 7 are repeated to evaluate the effect of the substitucion. Other options open to managers and planners for reducing uncertainties include redesigning a component, subsystem, or an entire system; undertaking $R \& D$ aimed at alleviating an uncertainty; exploring for new resources; or developing incentives for expanding manufacturing capacity.

Steps 3 through 6 have been automated by developing a computerized analysis program and a comprehensive data base of information on materials and the materials industry.

The analysis program is known as the Critical Materials Assessment Program (CMAP) and its functions are those enclosed by, the dashed line in Figure 6. CMAP can accumulate all requirements for a given material regardless of the ultimate usage of that material in a system. It can give the bulk and raw constituents of a material; calculate the impacts of a system's materials requirements relative to worldwide availability, source, demand, etc.; screen out materials that are of no concern; and identify those that are of concern. CMAP program operation is further described in Appendix A.

The data base currently contains about 2000 data entries covering more than 260 materials. Bulk material information includes estimates of present and future U.S. and world consumption, prices, U.S. imports, and dominant non-U.S. suppliers. Information on raw materials includes the same kind of data plus estimates nn U.S. and world rcserves and rconutisis.

The information base also includes data on the consumption of primary (including by-products) and serondary materials requi red to produce each unlc of standard bulk material.

Well over 100 information sources have been employed. The sources include many government publications, technical handbooks, special reports, technical papers, trade association and technical association data, journal articles and the like. Where no secondary source data are available, information has been obtained directly from producers. All data entries are referenced for further examination when necessary. A partial listing of references used is included in the reference list at the end of this report $(5-25)$. 
In short, the methodology contains a data base on most of the materials information planners and designers of systems will need, and the means for rapidly manipulating the information toward the desired end. Any information on materials which is not already contained in the data base can easily be added as required. This information then becomes part of the data base and is available to future users.

\section{USE OF THE METHODOLOGY}

We can best see how the methodology is applied by considering some of the actual applications to date. Results for application to two systems will be discussed - Solar Heating and Cooling of Buildings (SHACOB) and the Satellite Power System. SHACOB will be discussed first because the scenario studied represents a much smaller scale program than the SPS, and thus it is more amenable to a brief review of overall results. The SPS will then be discussed and emphasis will be placed on one SPS problem material - to provide an example of the type of followup analysis that is required when materials problems are identified.

\section{Solar Heating and Cooling of Buildings (SHACOB)(2)}

The "scenario" studied was a system comprised of equal mixtures of nine SHACOB systems (defined in Appendix B) using a total of 500 million square meters of collectors. Such a system would have a heat-producing capacity of about 0.7 Quad $\left(10^{15} \mathrm{Btu}\right)$. Construction was assumed to begin in 1985, to end in 2000, and to follow an exponential growth curve, with a maximum growth rate in any one year of about 15 percent.

The bulk and raw materials analysis and screening results from a CliAP analysis of this system are shown in Tables 1 and 2, respectively.

Eleven bulk materials, flagged* with asterisks in Table 1, exceeded one or more of two screening critcria:

- More than 50 percent of the supply comes as a by-product whose production is limited by the production of the principal product

- More than 50 percent of the U.S. supply is imported.

*The Computer program flags those materials which exceed preestablished threshold levels. The threshold values shown in Tables 1 and 2 were selected on the basis of judgment and experience. A detailed explanation of the key screening factors and their threshold levels is contained in Appendix A. 
TABLE 1. SHACOB BULK MATERIALS REQUIREMENTS ${ }^{(3)}$

(CMAP PRINTOUT)

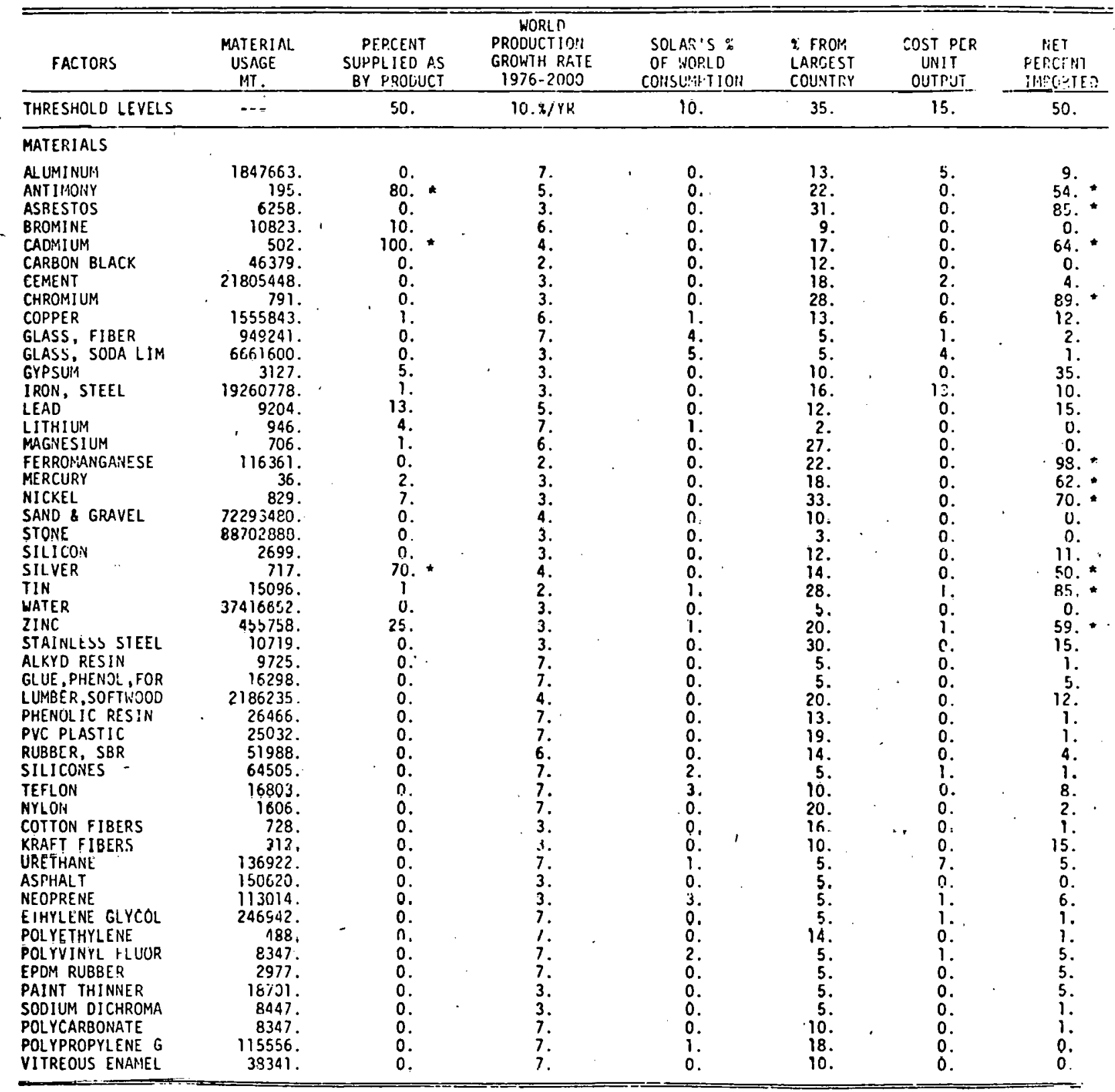

Note: $M T=$ metric tons

$*=$ threshold exceeded 
TABLE 2. SHACOB RAW MATERIALS REQUIREMENTS (3)
(CMAP PRINTOUT)

\begin{tabular}{|c|c|c|c|c|c|c|c|c|c|c|}
\hline FACTORS & $\begin{array}{l}\text { RAI } \\
\text { MAICRIAL } \\
\text { USAGE } \\
(1000 \text { STIT) }\end{array}$ & $\begin{array}{l}\text { WORLD } \\
\text { PROIJUCTN } \\
\text { GROWTH } \\
\text { RATE } \\
\end{array}$ & $\begin{array}{l}\text { MAX \& FOR } \\
\text { SOLAR IN } \\
\text { ONE YEAP } \\
\text { WORLD } \\
\end{array}$ & 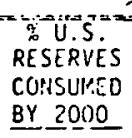 & 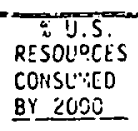 & 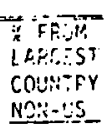 & 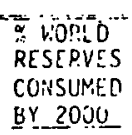 & 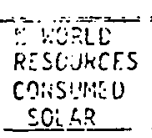 & $\begin{array}{l}\text { Sosts in } \\
\text { s/Ge of }\end{array}$ & 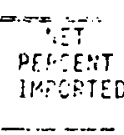 \\
\hline THRESHOLL iEVELS. & .... & $7 \% / Y r$ & 10. & 400. & 300. & 60. & 300. & 200. & 15. & sú. \\
\hline \multicolumn{11}{|l|}{ MATERIALS } \\
\hline ANTIMONY ORE & 20. & 5. & 0. & $1218^{*}$ & $1129 . *$ & 22. & 75. & 64. & 0. & 54. \\
\hline ASBESTOS & 7. & 3. & 0. & $539 . *$ & 28. & 31. & 190. & 129. & 0. & $85:$ \\
\hline BAUXITE & 9779. & 5. & 1. & $2235 . *$ & 298. & 31. & 14. & 9. & 0. & 91." \\
\hline $\begin{array}{l}\text { BORATE } \\
\text { BUTANE }\end{array}$ & 237. & 5. & 1. & 11. & 0 & 50. & 10. & $0:$ & 0. & 3. \\
\hline $\begin{array}{l}\text { BUTANE } \\
\text { CHROSiITE }\end{array}$ & $\begin{array}{l}59 . \\
19 .\end{array}$ & 3. & 0. & $3351 . *$ & $424 . *$ & 23. & 17. & 4. & 0. & \&. \\
\hline AY & 3376. & 2. & 0. & 0. & 0 & 12. & 0 . & 0. & 0. & 0. \\
\hline & 31100. & $i$ i. & 0. & 6. & 1. & 160 & 13. & 1. & 1. & 0. \\
\hline BITUM/LIGHT & 17666. & $i$. & 0. & 6. & $\because$ & 7. & 13. & $i$. & $i$. & 0. \\
\hline III & 342711 . & 6. & $i$. & 1002. & $439 . *$ & 13. & 85. & 25. & 2. & 12. \\
\hline FELOSPA! & 628 & 3. & $i$. & 5. & 0 & 8. & 13. & 0. & 0. & 0. \\
\hline FLUORSPAR & 325. & 5. & 0. & $704 . *$ & 151. & 19. & 200. & 120. & c. & 79. \\
\hline GYPSLIM & 1051. & 3. & 0. & 175. & 0. & 10. & 11. & 0. & 0. & 35 \\
\hline IRON ORE & 112468. & 5. & 0. & 56. & 7. & 27. & 15. & 6. & 0. & 23. \\
\hline $\begin{array}{l}\text { LEAD ORE } \\
\text { LeR }\end{array}$ & 609 . & 3. & 0. & 77. & 38. & 12. & 126. & 13. & 0. & 15. \\
\hline $\begin{array}{l}\text { LITHIUM ORE } \\
\text { LITI }\end{array}$ & 407. & $7 . *$ & $i$. & 53. & 19. & 24. & 49. & $i 7$. & 0. & 0. \\
\hline MANGANESE ORE & 657. & 3. & 0. & 100. & 4. & 22. & 6. & 11. & 0. & 96. \\
\hline MERCUR & $i$. & i. & 0. & 384. & $573 . *$ & 18. & 13. & 36. & 0. & 62. \\
\hline NATURAL GAS & 2628. & 5. & 0. & 245. & 277. & 23. & 93. & 9. & 0. & 5 \\
\hline NICKEL ORE & 169. & 3. & 0. & $44310^{*}$ & $5317 . *$ & 33. & 54. & 23. & 0 . & 70. \\
\hline NITROGEN, FIXED & 0. & 4. & 0. & 0 & 0. & 5. & 0. & 0. & 0. & 10. \\
\hline OXYGEN & 38. & 4. & 0. & 0. & 0. & 22. & 0. & 0. & 0. & 0. \\
\hline PETROLEUM & i976. & 3. & 0. & $562 . *$ & 210. & 18. & 110. & 36. & 0. & 39. \\
\hline SALT & 11724. & 6. & 0. & 0. & 0. & 18. & 0. & 0. & 1. & 7. \\
\hline SAND/GRA:E: & 78555. & 4. & 0. & 0. & 0. & 6. & 0. & 0. & 0. & 0. \\
\hline SILVER ORF & 5111. & 4. & 0. & 373. & 99. & 14. & 208. & 56. & 0. & 50. \\
\hline SODIUM NITRATE & 1. & 4. & 0. & 0. & 0. & 16. & 0. & 0. & 0. & 1. \\
\hline STONE & 88703. & 3. & 0. & 0. & 0. & 3. & 0. & 0. & 0. & 0. \\
\hline SULF & 512. & 3. & 0. & 93. & 1. & 14. & 90. & 0 . & 0. & 0. \\
\hline $\operatorname{TIN} 0$ & 150963. & 2. & 1. & $4369 . *$ & $1311 . *$ & 20. & 73. & 20 . & 0. & $85 . *$ \\
\hline ZINT ORE & 8217. & 0. & 1. & 148. & 34. & 20. & 154. & 8. & 0. & $55 . .^{*}$ \\
\hline COTTON & 1. & \&. & 0. & 0. & 0. & to. & 0. & 0. & 0. & 1. \\
\hline FLAX SEED & 55. & 1. & 0. & 0. & 0. & 25. & 0. & 0. & 0. & 20. \\
\hline -PRODUCTS & 1. & 3. & 0. & 0. & 0. & 20. & 0. & 0. & 0. & 1. \\
\hline LUMBER & 2208. & 1. & 0. & 0. & 0. & 12. & 0. & 0. & 1. & 18. \\
\hline SEA WATER & 173723. & 0. & 0. & 0. & 0. & 0. & 0. & 0. & 0. & 0. \\
\hline $\begin{array}{l}\text { SOYBEAN } \\
\text { WATER }\end{array}$ & $\begin{array}{l}28 . \\
97680 .\end{array}$ & 3. & 0. & 0. & 0. & $\begin{array}{l}12 . \\
5\end{array}$ & 0. & 0. & 0. & 0. \\
\hline $\begin{array}{l}\text { WAER } \\
\text { WHEAT }\end{array}$ & $9 / 080$. & 3. & 0. & 0. & :. & 10. & 0. & 0. & 0. & 0. \\
\hline MISC. & 763. & 0 & 0. & 0. & 0. & 0. & 0. & 0. & $i$. & $0:$ \\
\hline STEAM & 71634. & 5. & 0. & $i$ & 0. & 10. & 0. & 0. & 0. & 0. \\
\hline LIMEST & $51586^{\circ}$. & 3. & 0. & 0. & 0. & 20. & 0. & 0. & 0. & 2. \\
\hline COAL, BY-PROD & 209934 . & $i$. & $i$. & 6. & $i$ & 7. & 13. & $i$. & 0. & 0. \\
\hline ELECTRICITY & 1107392. & 3. & 0. & 0. & 0. & 0. & 0. & 0. & 0. & 0. \\
\hline & 81053. & $i$. & 0. & 6. & 1. & 7. & 13. & $i$. & 0. & 0. \\
\hline PETROLEUM & 7682. & 3. & 0. & $563 . *$ & 210. & 18, & 110. & 36. & 0. & 39. \\
\hline
\end{tabular}

Note: $M T=$ metric tons

* = threshold exceeded 
Analysis, however, showed that these flagged materials pose no supply problem. In all cases, consumption for $S H A C O B$ use 1 s only a small part of world consumption and constitutes only a small part of the system's total cost. Since consumption for solar use is low, these materials should be available in the quantities required for solar energy systems even if the total U.S. supply is limited by cartels, political action, or reductions in production. If the supply of a particular material is limited and competition for it increases, prices will probably go up. But even then, a large price increase would be required to place the material's cost contribution to the system's total cost at an unacceptable level and force the use of substitutes.

The same type of reaconing was used in classifying the 14 raw materials flagged in Table.2. One criterion was the same as those. just discussed--net percent imported. Again, the effect is minimal because the usage and costs of these raw materials are low.

Three other raw materials criteria were flagged for one or more materials in the SHACOB application:

- More than 400 * perçent of U.S. reserves consumed by the year 2000

- More than 300* percent of U.S. resources consumed by the year 2000

- More than 7 percent increase required in world production growth rate.

Exceeding the criteria for U.S. reserves and resources means either that more of the raw material will be imported in the futurc or that U.S. reserves and resources will hatve to increase. Historically, reserves and resources have generally increased with time due to continued exploration, development, and improved technology or higher prices which shift previously uneconomic deposits into the reserve category. Whether or not U.S. reserves and resources increase, the raw materials will be available worldwide in sufficlent amounts since the criteria for world reserves and resources were not exceeded. Again, supply disruptions will have little effect hecause the uoage aul cusls of these materials for the SHACOB system are small. Appendix $C$ contains. additional details on reserves and resources.

Only one material--lithium ore--had a required world production growth rate that exceeded the 7 percent threshold level. Once again, however, the small requirement for this material in the SHACOB system will be satisfied even if world production does not meet demand. Even with higher prices resulting from demand exceeding supply, lithium costs will remain a very small part of the system's total costs.

* See Appendix C for explanation of these values. 
In summary, barring extreme shifts in the current pattern of supply, none of the SHACOB bulk or. raw material demands of the scenario studied appear to be cause for significant concern.

\section{Satellitè Power System}

The methodology was also applied to the Satellite Power System mentioned earlier. The scenario studied assumed a total of 60 satellites, each rated at 5 gigawatts of output to the utility distribution system. In the scenario, the first two satellites are scheduled to be operational in the year 2000. Two more' will be completed each year through 2029, providing the full 300-gigawatt (60-satellite) operational system.

The major components of SPS are:

- Launch vehicles for transporting cargo and personnel into low-earth orbit (LEO)

- Facilities and equipment in LEO for fabricating and assembling satellites and support facilities

- Vehicles for transferring cargo and personnel into geosynchronous orbit (GEO)

- Facilities for constructing and operating the satellites in GEO

- Satellites consisting of photovoltaic arrays

- Microwave power transmission equipment

- Ground antennas for receiving microwave transmissions and equipment for conversion and utlity interfacing.

A systems definition of the SPS may be found in "Satellite Power System Concept Development and Evaluation Program" (Reference system Report). (26) An excellent description of the SPS is contained in a 'paper by Christopher C. Kraft, Jr.(27) Figure 7 is an artist's sketch of one SPS satellite and a ground-receiving antenna.

Materials assessments were carried out for two alternative SPS systems. One system was based on silicon photovoltaic solar cells and the other on gallium arsenide cells. Tables 3 and 4 show the bulk and raw materlal analysis and screening resilts for the 295-gigawatt operational silicon system ${ }^{*}$ (requirements for the first 5-gigawatt developmentai system are omitted because they are atypical of the requirements for the

*Similar data for the gallium arsenide system are shown in Appendix D. 


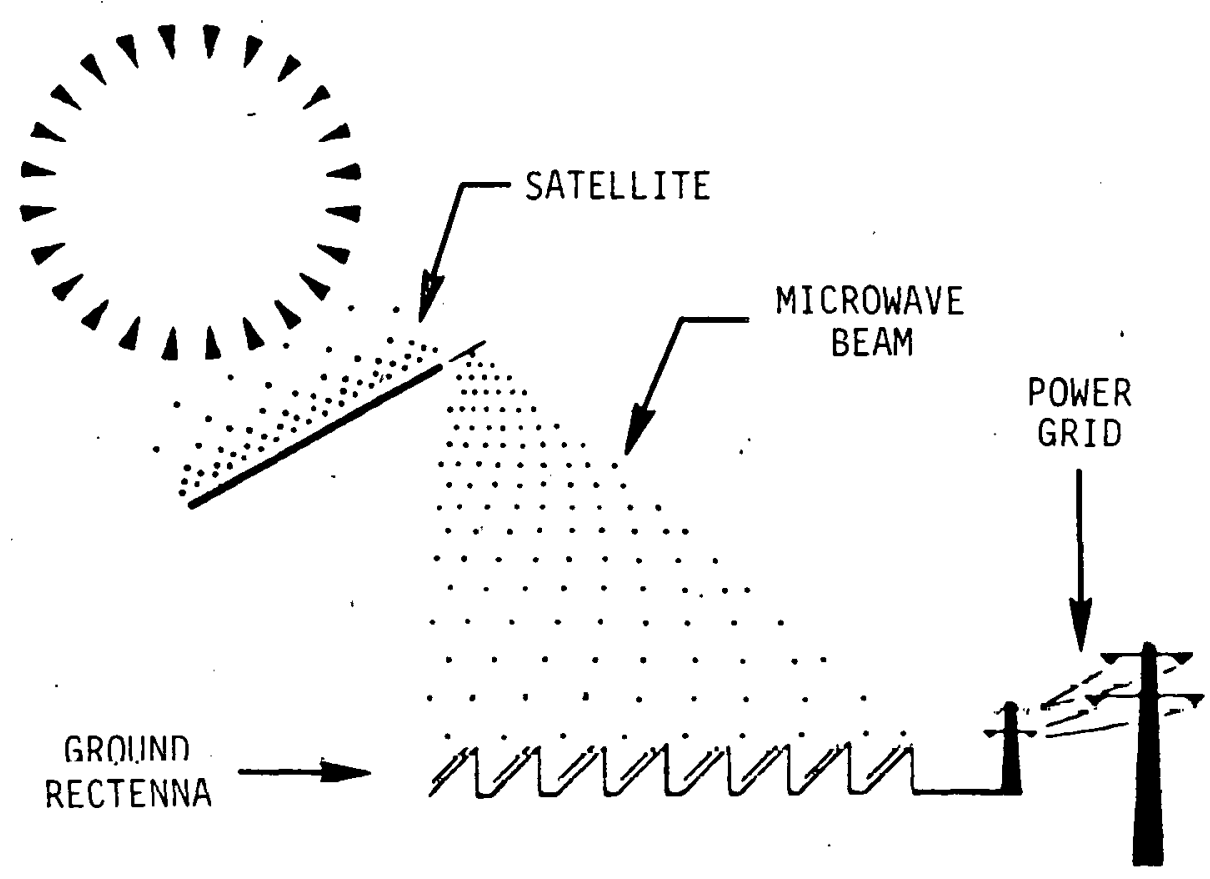

FIGURE 7. SOLAR POWER SATELLITE

(27)

remaiping 295 gigawatts of output). The data include the materials required for the satellites, four separate transportation systems, and construction of assembly facilities both in low-earth orbit and geosynchronous orbit. They also include materials for construction of the ground-based antenna system which will collect and convert SPS output.

Several materials are seen to exceed threshold criteria (a few exceed two or more criteria), calling for further $\varepsilon$ tudy. The following brief discussion considers some implications of these data and possible remedial strategies for one material--graphite fiber.

Under current thinking, graphite fiber reinforced thermoplastic (GFRTP) will be the basic structural load-bearing material for the SPS satellite, as well as for the construction facilities in space. GFRTP is here assumed to be about 60 percent graphite fiber and 40 percent polysulfone thermoplastic. The graphite fiber is most commonly produced from polyacrylonitrile (PAN) fiber.

Based on information contained in the dato hage, the CMAF bcreening program produced the following total requirements ${ }^{\star}$ for these principal bulk materials for the 295-gigawatt system:

Graphite Fiber

PAN Fiber

Polysulfone
225,000 metric tons

508,000 metric luns

150,000 metric tons

* Slight differences between the requirements listed here and the quantities shown in Table 3 are due to the system's, other minor requirements for these materials. 
TABLE 3. BULK MATERIALS REQUIREMENTS - 295-GIGAWATT-SILICON OPTION (CMAP PRINTOUT)

SOLAR SCENARIO:

INTRODUCTION YEAR- 2000

CUMULATIVE CAPACITY 2029- 295. GW

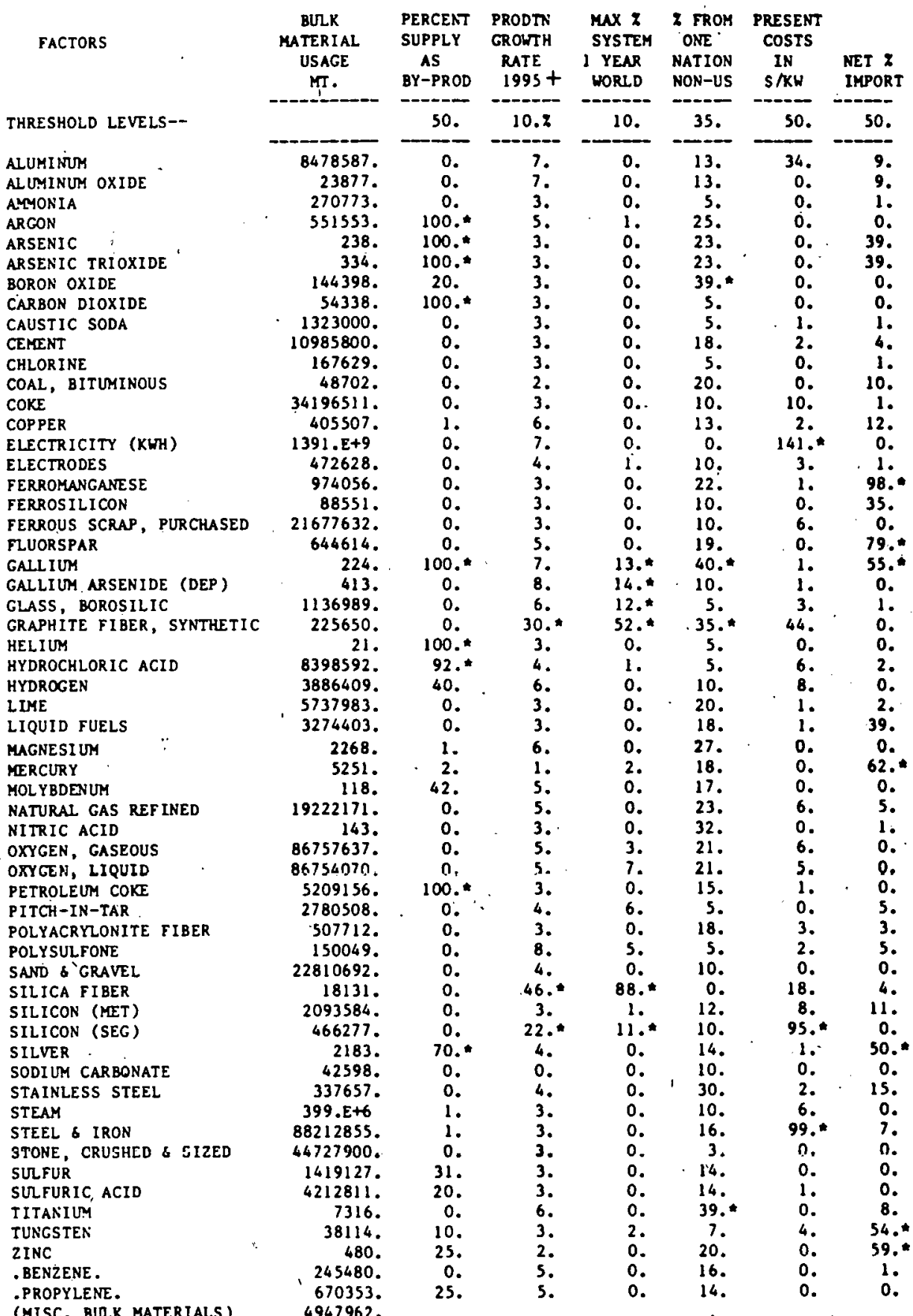

Note: $+\because$ Beginning in 1995 
TABLE 4. RAW MATERIAL REQUIREMENTS FOR SOLAR POWER

, SATELLITE OPERATIONAL SYSTEM (SILICON)

SOLAR SCENARIU:

INTRODUCTION YEAR- 2000

CUMULATIVE CAPACITY 2029- 295. GW

FACTORS

THRESHOLD LEVELS--

BAUXITE

BAUXITE, BY PROD

BORON OXIDE

CEROMITE

CLAYS

COAL, BITUMINOUS

COPPER BYPROD.

COPPER ORE

FLUORSPAR ORE

GYPSUM, . CRUDE

IRON ORE

LIMESTONE

MANGANESE ORE

MERCURY ORE

MOLYBDENUM ORE

NATURAL GAS

NICKEL ORE

PETROLEUM

RUTILE (CONC.)

SALT

SAND \& GRAVEL

SILVER ÜKE

SODA ASH (NAT.)

STONE

SULFUR ORE

TIMBFR, LIMAER

TUNGSTEN ORE

HATER, SEAHATER

ZINC ORE
TPRD MNA ZUS ZIS TFRM TWORLD ZWORLD

RAW GROW SYST RESERV RESOUR ONE RESERV RESOUK PRSNT

MATERIAL RATE ONE CONSUM CONSUM NAT CONSUM CONSUM COSTS

USAGE FROM YEAR BY BY NON- BY BY IN NET (1000MT)

1995 WRLD 20292029 US 20292029 S/KW IMPT

\begin{tabular}{rccccccccc} 
& 7. & 10. & 400. & 300. & 60. & 300. & 200. & 50. & 50. \\
\hline 39903. & 5. & 0. & $19125 . *$ & 2588. & 31. & 89. & 58. & 2. & 91. \\
11213. & 5. & 0. & 19055. & $2579 . *$ & 31. & 89. & 58. & 0. & 91. \\
146. & 3. & 0. & 120. & 30. & 39. & 64. & 16. & 0. & 0. \\
259. & 3. & 0. & 100. & 3852. & 28. & 399. & 6. & 0. & 89. \\
1582. & 2. & 0. & 0. & 0. & 12. & 0. & 0. & 0. & 0. \\
771721. & 2. & 1. & 25. & 3. & 7. & 26. & 2. & 40. & 0.
\end{tabular}

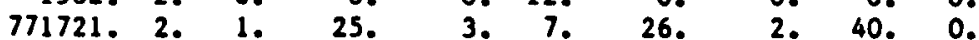

1. 4. 0. 299. 68. 13. 316.* 77. 0. 12.

57931. 4. $0.499 .68 .13 .316 .27 . \quad 0.12$.

1960 . 5. 0. 6814.*1143.*19. 1402.*769.* 0. 79.*

527. 2. $0.618 . * 0.10 .373 . * 0.00 .35$.

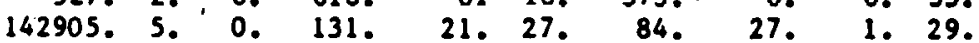

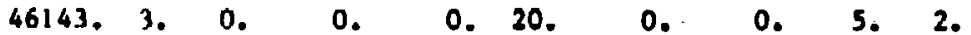

2143. 3. "0. 100. 25. 22. 52. 26. 1. 98.*

181. 1. 2. 643.* 291. 18. 280. 83. 0. 62.*

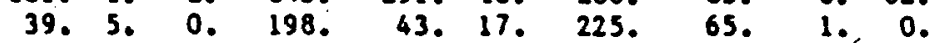

47425. 5. 0. 698.* 163. 23. 501.* 50. 15. 5.

2836. 2. 0. 11578. 30. 33. 160. 67. 0. 70.*

329090. 2. 0. 2327* 761.*18. 343.*113. 81.*39.

16. 5. $0.605 . * 199.99 . * 53.42 .00 .98 . *$

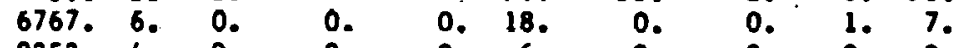

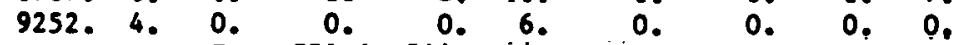
3122. 4. 0. 921.* 244. 14. 990.*266.* 0. 50.* 112. 5. 0. 4. 2. 2. 3. 1.00 .0$.

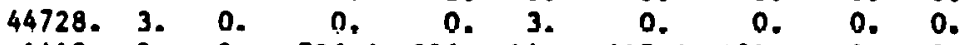
1419. 3. $0.726 . * 236.14 .417 . * 131.0 .0 .00$. 2146. 1. 0. 0. 0. 12. 0. 0. 1. 18. 6365. 3. 2. 1441.*.414.*21. 275. 96. 1. 54.*

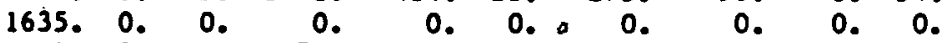
11. 3. $0.672 . * 403 . * 20.436 . * 282 . * 0.59 . *$

In lee: + - Begluming In 1995

\pm - Threshold exceeded

MT = Metric tons 
For the first operational year, 7600 metric tons of graphite fiber and 5100 metric tons of polysulfone will be required. Production of the 7600 metric tons of graphite fiber will require about 17,200 metric tons of PAN fiber.

The next step was to examine the requirements for constituent materials to produce graphite fiber and polysulfone. These relationships are approximately as shown in Figure 8 .

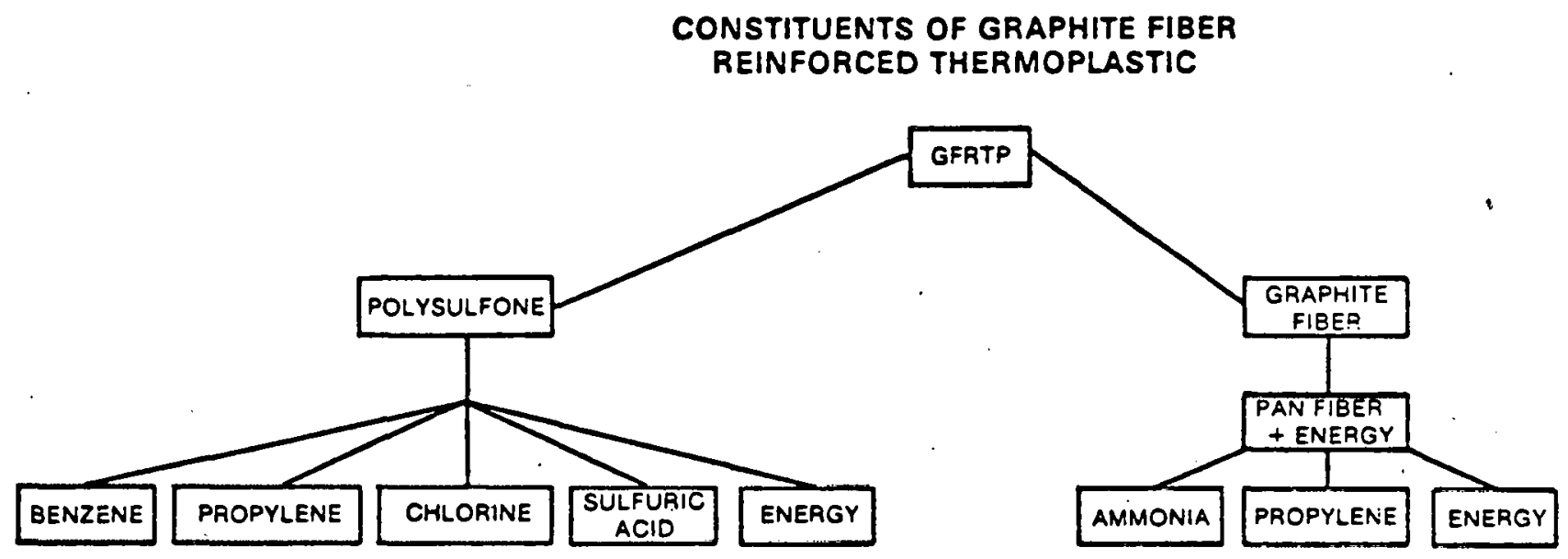

FIGURE 8. CONSTITUENTS OF GRAPHITE FIBER AND POLYSULFONE

In the CMAP screening analysis, none of these materials exceeded the criteria, as shown in Table 5 .

TABLE 5. CONSTITUENT MATERIALS FOR PAN FIBER AND POLYSULFONE

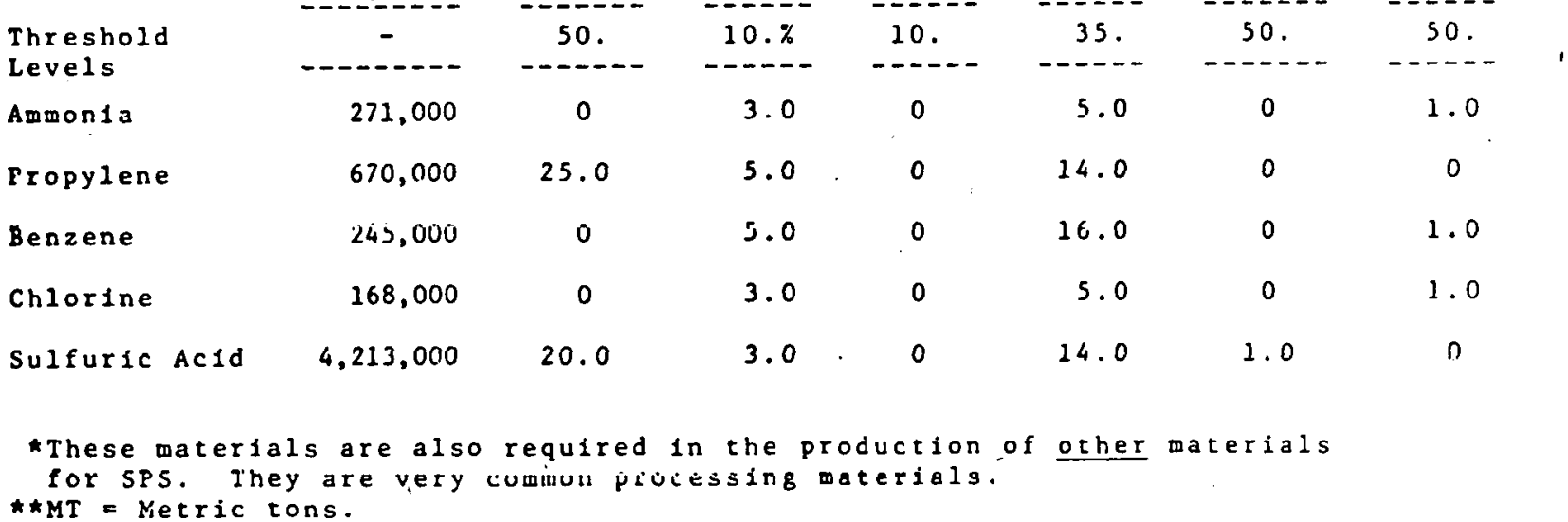


Consequently, the major uncertainty connected with GFRTP is the capacity to manufacture graphite fiber. For that reason, the analysis turned to a closer inspection of the graphite fiber data base and the underlying technology.

Much of the future growth for carbon/graphite ( $C / G)$ fiber is based on its prospective widespread use in plastic composites by the automobile industry. If these prospects are realized, a growth rate of about 15 percent per year is expected over the next 10 to 20 years. If not, the growth in production of $\mathrm{C} / \mathrm{G}$ fiber may be relatively slow--perhaps 3 to 5 percent per year. If the high growth rate prevails, a very substantial increase in U.S. and world production capacity will be necessary.. (Currently, one U.S. producer is building an $360 \mathrm{mt} / \mathrm{yr}$ plant. The plant is based on Japanese-licensed PAN technology).

- Figure 9 illustrates that, to meet SPS demands in the year 2000 , the $\mathrm{C} / \mathrm{G}$ fiber industry's production will need to increase 30 percent per year (assuming that the automobile industry will make widespread use of $\mathrm{C} / \mathrm{C}$ fiber). We also can calculate that, beginning in the year 2000 , SPS would consume 52 percent of world production--a market/price position of serious concern.

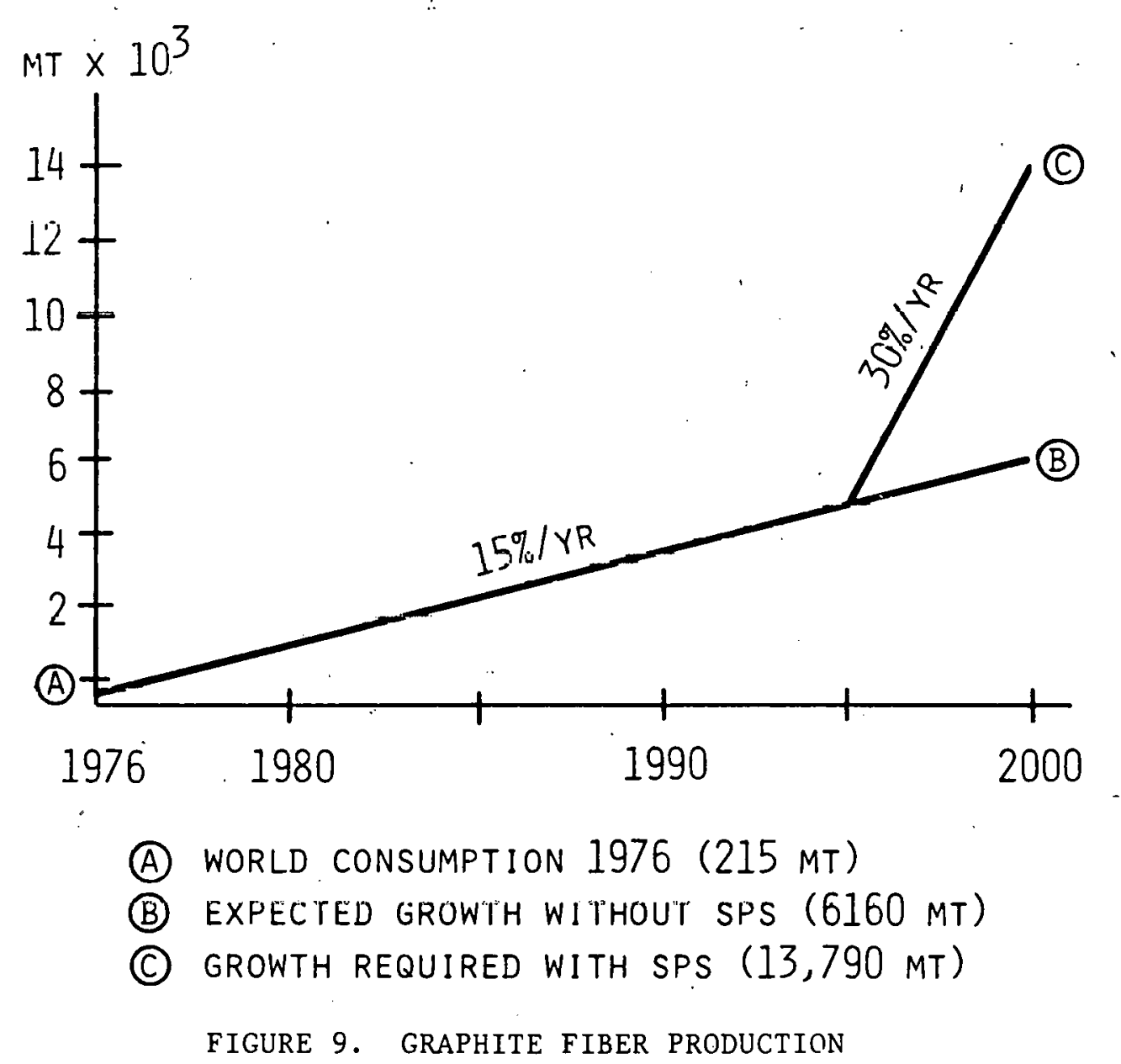


This analysis is still incomplete in that it deals with the aggregate of all C/G fiber. It also assumes that all fiber is produced from.PAN, which is the current trend. Planners and designers need to undertake a more detailed analysis in considering the ramifications of a new system's impact on materials' supply and demand, such as that described in the following paragraphs.

Carbon/graphite fiber technology is complex. The fiber is currently produced from one of three materials, PAN (the most common), viscose rayon, or pitch (used in a developmental process). There are many grades and specifications of each of these precursor materials. For certain very demanding aerospace structural applications, a fiber with high elastic modulus (over 50,000,000 psi) may be specified.

Both PAN and rayon fibers are based on plentiful constituent materials (ammonia and propylene for PAN and wood pulp for rayon) and, therefore, there is no concern over their raw material requirements. However, U.S. production of these special fibers is currently very limited.

Current thinking indicates that the GFRTP in the SPS system will incorporate high-modulus graphite fiber using a rayon precursor. Although high-modulus graphite yarns can be made from both PAN and rayon, the rayon-based graphite yarns reportedly have lower density, lower thermal conductivity, and lower coefficients of thermal expansion. These qualities might make them the preferred technical candidates for SPS structures.

In 1977 , the U.S. production capacity for this special rayon was about 13,000 to 14,000 metric tons. However, the production capacity for high-modulus, continuous $C / G \mathrm{f} 1$ ber yarn based on this type of rayon was only about 3 metric tons, and that by a single manufacturer. And, the continued operation of even that one plant is reportedly uncertain.

Furthermore, the production yield for rayon-based graphite fiber is only about 20 percent. Thus, the current capacity of 14,000 metric tons of rayon wnild produce only 2800 metric tons of graphite yarn annually-about 37 percent of the SPS requirements for the year 2000 .

And finally, these high-modulus, rayon-based $C / G$ fibers cost from $\$ 660$ to $\$ 990$ per $\mathrm{kg}$, whereas the current price used in the data base $(\$ 57.20 / \mathrm{kg})$ is an average for all types of graphite fiber. Hence, to consider the optimum final material, the screening factor "present costs in $\$ / \mathrm{KW}^{\prime}$ should increase at least 10 times, from $\$ 44 / \mathrm{KW}$ to about $\$ 440 / \mathrm{KW}$. This would be the highest material cost contribution in the system.

It is apparent, then, that further detailed analysis and planning of graphite fiber use is needed if SPS requirements are to be mét. First, a decision must be made as to which kind of fiber will be needed. Following that, various options for achieving the required quantities can he explored. R\&D might be launched, for example, to develop better, 
less costly methods of producing large quantities of $\mathrm{C} / \mathrm{G}$ fiber. Procurement of growing quantities of precursor fiber for finished $C / G$ fiber in advance of actual need could provide the necessary incentive for the industry to expand its capacity. (This avenue raises another question, however, of preventing deterioration of the precursor fiber while in storage.) Other expansion incentives could be explored. The impact of substituting other materials for GFRTP will need continuing study.

\section{CONCLUDING REMARKS}

Experience with the materials assessment methodology has demonstrated its potential value to policy makers, planners, and designers. For the first time, materials analyses of competing systems and designs are possible on a truly comparative basis, since they can all be performed using the same data base. This should eliminate barriers that currently exist solely because we've been forced to compare "apples to oranges". Communications breakdowns can be avoided. Further, the methodology enables (and actually encourages) "what-if" analyses since it makes them--again for the first time--relatively easy to perform. This factor alone can ensure more efficient, more effective, less costly systems.

To summarize the benefits, use of the methodology will:

- Provide a better basis for decision-making

- Minimize uncertainties regarding materials availability

- Provide lead time if R\&D or major expansions of manufacturing capac1ty prove necessary

- Save time and money

- Guide decisions as to the tining and ultimate size of new systems.

- Raioc the oucccoo probability of major new systems ventures. 


\section{REFERENCES}

(1) Litchfield, J.W., Watts, R. L., et al., "A Methodolgy for Identifying Materials Constraints to Implementation of Solar Energy Technologies", Battelle Pacific Northwest Laboratories, Richland, WA, July, 1978 .

(2) Watts, R. L., Gurwe1l, W. E., et al, "Some Potential Material Supply Constraints in the Deployment of Photovoltaic Solar Electric Systems", Battelle Pacific Northwest Laboratories, Richland, Washington, September, 1978.

(3) Watts, R. L., Gurwell, W. E., et al, "Some Potential Material Supply Constraints in Solar Systems for Heating and Cooling of Buildings and Process Heat", Battelle Pacific Northwest Laboratories, Richland, Washington, September, 1978.

(4) Teeter, R. R., and Jamieson, W. M. "Preliminary Materials Assessment for the Satellite Power System", Battelle Columbus Laboratories, September, 1979 .

(5) Commodity Data Summaries 1978. Bureau of Mines, U.S. Department of Interior, Washington, DC 1978.

(6) Mineral Facts and Problems (Bicentennial Edition). Bureau of Mines. Bulletin 667, U.S. Department of Interior, Washington, DC 1975.

(7) Chemical Marketing Reporter (Weekly)., Schnell Publishing Co., New York, NY.

(8) Facts and Figures of the Plastics Industry. The Society of the Plastics Industry, New York, NY 10017, 1977.

(9) Chemical Statistics Handbook. Manufacturing Chemists Association, Washington, DC 20009, 1971.

(10) Modern Plastics. (Monthly).

(11) Current Industrial Reports. Series M30A, U.S. Department of Commerce, Bureau of Census, Washington, DC.

(12) Synthetic Organic Chemicals. U.S. International Trade Commission, Washington, DC.

(13) Current Industrial Reports. Series M32J, U.S. Department of Commerce, Bureau of Census, Washington, DC.

(14) Monthly Energy Review NTISUB/D/127-002 U.S. Department of Energy, Energy Information Administration, National Energy Information Center, 1978 : 


\section{REFERENCES (CONTINUED)}

(15) Young, J.F., Materials and Processes, Second edition, John Wiley and Sons, New York, 1954.

(16) ASM, Metals Handbook, Eighth edition, Volume l, Properties and Selection of Metals, American Society for Metals, Metals Park, OH 1961 .

(17) ASM, Metals Handbook, 19.48 edition, American Society for Metals, Metals Park, OH, 1948.

(18) Kingery, W. D., Introduction to Ceramics, John Wiley and Sons, New York, 1960.

(19) Data Book 1977, Metals Progress, Vol: 112, No. 1, June, 1977.

(20) 1975 Materials Selector, Materials Engineering, Vol. 80, No. 4, September 1976.

(21) Unified Numbering System for Metals and Alloys, Society for Automotive Engineers, Warrendale, PA, January, 1975.

(22) Energy Use Patterns in Metallurgical and Nonmetallic Mineral Processing, Bureau of Mines (Battelle, 1975).

(23) Industrial Chemicals., Farth, Keyes, and Clark, 4th Edition.

(24) Chemical Economics Handbook, Stanford Research Institute, Menlo Park, California..

(25) Sources and Production Economics of Chemical Products, McGrawHil1, 1974 .

(26) "Solar Power Satellite Concept Evaluation Program", Department of Energy and National Aeronautics asnd Space Administration, Washington, DC, October, 1978.

(27) Kraft, C. C., "The Solar Power Satellite Concept--The Past Decade and the Next Decade", AIAA Paper No. 79-0534, Presented at the AIAA 15th Annual Meeting and Technical Display, Washington, D.C., Fubruary 6-8, 1979. 
APPENDIX A

CMAP SCREENING PROCESS

\section{CMAP Program Operation}

CMAP performs three principal functions: (1) calculation of total materials requirements; (2) determination (for each material) of a set of parameters that characterize the materials' demand impact; and, (3) comparison of the parameter values so determined with certain "threshold" values for those parameters, which, when exceeded, signify potential problems. When threshold values are exceeded, "flags" are set on the output printout that call attention to the potential problem.

Figure A-1(1) depicts CMAP program operation. To facilitate and increase the flexibility of analyses, CMAP has been made interactive. This means that input data can be changed while cases are being examined. Thus, the top blocks of user-supplied impact can be changed to analyze desired case variations (e.g. different scenarios) and/or to iterate based on results. The botton left blocks contain the baseline system design characterization (material requirements) and the materials

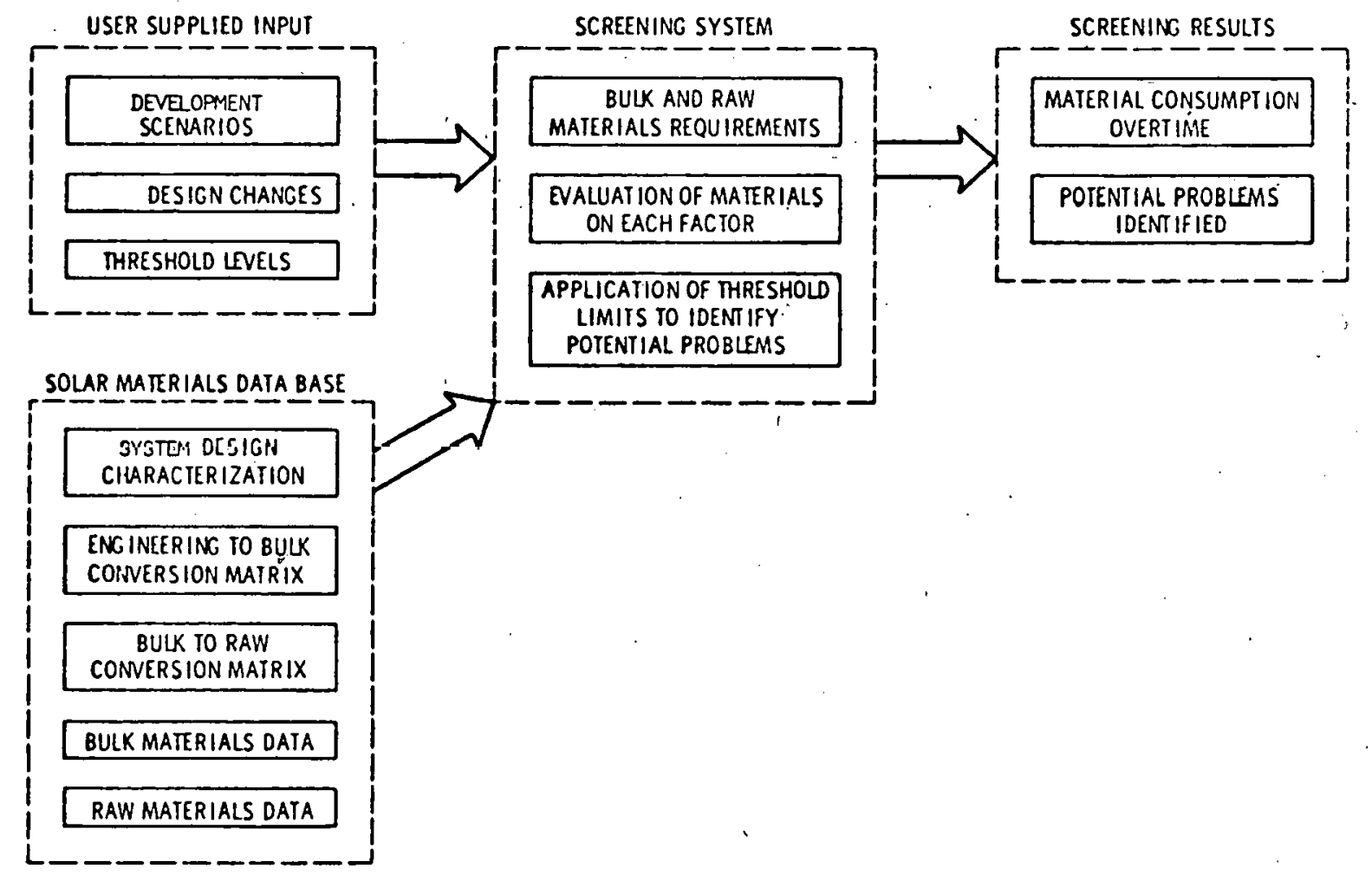

FIGURE A-1. SCREENING SYSTEM (1) 
data base which are entered by card deck. These data cannot be changed interactively, but can be updated periodically as needed.

Calculation of materials requirements begins with the system materials list. Total amounts of the materials on that list required to support a specified program scenario are calculated. Then, using information stored in the materials data base, production processes required to produce those materials are analyzed to determine secondary bulk material and raw material requi rements.

Once total materials demand has been established attention turns to the material parameters and threshold values on which the screening is based. Since the parameters of interest and threshold values differ somewhat for bulk and raw materials, the screening of these two types of materials is done separately (separate output printouts are produced).

Before proceeding with a general discussion of the screening process, a few additional words regarding the threshold values used are in order. One of the parameters of interest for bulk materials is the production growth rate required to meet the demand of the SPS and all other industries (retrievable from the materials data base). The threshold value for this parameter is currently set at $10 \%$ per year. Thus, if the required growth rate exceeds $10 \%$ a flag is set on the printout signifying that a potential production capacity problem exists. If the material in question has a relatively small production base (e.g. graphite reinforced thermoplastic) then a $10 \%$ growth rate might not be difficult to achieve. However, if the material in question already has a large production base (e.g. aluminum) then a $10 \%$ growth rate would represent an enormous requirement for additional capital, labor, facilities, etc., and a definite problem exists.

Thus, in reality, an accurate "threshold value" for a given parameter might be different for each material considered. However, any attempt to incorporate this reality into CMAP would make the automated screening intractable and defeat its entire purpose. Therefore a single threshold value is postulated for each parameter-a value, based on Battelle's experience, that is representative and generally conservative for the majority of materials. These threshold values are not intended to be absolute measures of material criticality, but merely indicators that can speed and simplify the analysis of results. The responsibility for accurately interpreting those results properly remains the task of the experienced analyst.

\section{Bulk Materials Screening Parameters and Thresholds}

The parameters of interest for bulk materials are listed below. These parameters are determined for each material required.

- Percent of the material which is produced as a by-product of another material production process 
- World production growth rate (per year) requi red to meet SPS and all other projected demands

- Maximum percent demand (in any given year) of the SPS as a portion of total world demand

- Percent of the world production attributable to a single foreign source

- Material purchase cost contribution to SPS power installed, $\$ / \mathrm{KW}$

- Net percent of U.S. material consumption that is imported (from all foreign sources).

In the following paragraphs these parameters are discussed, the rationale for assessing criticality is developed, and currently used threshold values are identified.

Percent Supplied as By-Product. The threshold value is set here at 50 percent. The frequent implication that by-product dependence is constraining is often misleading. Materials sometimes considered today as by-products may be viewed at other times as co-products or even primary products depending upon supply/demand and market/price conditions. Hence the term by-product material should not necessarily be viewed as a "low-cost" or an "undesirable" material production consequence of a process stream. The economics of many extractive and manufacturing processes are highly dependent upon by-product/co-product recovery. That economic dependence or leverage frequently becomes important in assessing criticality of the material. However, where economic dependence is not present, only strong demand and attractive market prices will bring forth the capital investment required to recover the amounts of the by-product material needed.

Growing demand for the primary product is of basic importance to sustaining given levels of by-product production. If the system requirements for the by-product material are small, or if the market is "glutted", even declining primary material production levels can maintain adequate by-product supplies.

World Production Growth Rate. The threshold value here is 10 percent. Many small volume or new materials can readily maintain a 10 percent annual rate of growth. However large volume, capital intensive commodities would have great difficulty in sustaining such a growth rate. Therefore any growth rate over 5 percent for high volume commodity materials, raw or bulk, should also be reviewed.

Maximum Percent System Demand, One Year World. This threshold is set at 10 percent. This figure represents the system's market impact on material consumption at its potentially highest demand level relative to demand for that material for other uses. At high percentage of demand levels, the system demand can be a market driver, pcrhaps bringing about 
higher prices or even cartelization. This criterion may also be viewed as a trigger for closed examination of opportunity costs--that is, the systems potential for adverse impact on other segments of the economy demanding the same material.

Percent From One Nation, Non-U.S. This threshold level is set at 35 percent. It represents a measure of supply domination in world markets by any one non-U.S. nation. If the system material demand is also a significant proportion of total demand, then potential for supply disruption or cartelization is present. The nature of the material demand, as well as the dominant nation identified, then becomes a part of the criticality judgment. This criterion usually assumes more importance in assessing raw materials, since bulk material production among industrial nations tends to disperse over time.

Present Costs in $\$ / K W$. This threshold is set at $\$ 50.00$ per $\mathrm{KW}$ of constructed capacity. This value is calculated as MT required $x \$$ per $\mathrm{MT} / \mathrm{system}$ capacity in $\mathrm{KW}$. Values for material in excess of the $\$ 50.00$ threshold deserve close examination. It should be emphasized that these figures represent present bulk material cost--not the present cost of fabricated components. The fabrication cost of many materials can very substantially exceed the materials cost per se. Stated costs also are representative of the prevailing art for producing the materials--often in low volumes in the case of new materials. For many newer materials, those production costs can be expected to be lowered over time.

Total cost of the system attributable to these materials becomes sensitive to changes in price or required volume of the materials in question. Materials price forecasts, fabrication cost determinations, design review and possible materials substitutions might be considered.

Net Percent Imported. The threshold value is set at 50 percent and is based on current levels of net U.S. imports. If the maximum volume of material required by the system is very small compared to total U.S. demand in the same time frame, there is probably little cause for concern regardless of the U.S. import level. For many materials--particularly raw materials--for which the U.S. is dependent on imports, that dependency is likely to grow in future years. This is a matter of general economic concern and not necessarily related to any specific system under consideration. In other words, we would be concerned only if the system design and its construction scenario might substantially exacerbate an already recognized U.S. import dependency for certain materials.

\section{$\underline{\text { Raw Materials Screening Parameters and Thresholds }}$}

With respect to the screening of raw materials levels of current reserves and resources estimates are introduced as screening parameters, in addition to those identified in the bulk material discussion. In general, where the U.S. is reserve/resource deficient, it is also import dependent. The focus of concern in these cases is levels of world reserves and resources and whether the system construction would 
substantially contribute to world resource deficiency or to substantially greater U.S. import dependency. The complete list of raw material screening parameters is given below.

- World production growth rate (per year) requi red to meet SPS and all other projected demands

- Maximum percent demand (in any given year) of the SPS as a portion of total world demand

- Percent of U.S. reserves consumed by the SPS and all other projected demand

- Percent of U.S. resources consumed by the SPS and all other projected demand

- Percent of world reserves consumed by the SPS and all other

- Percent of the world production attributable to a single foreign source

- Percent of world resources consumed by the SPS and all other projected demand

- Material purchase cost contribution to SPS power installed, $\$ / \mathrm{KW}$

- Net percent of U.S. material consumption that is imported (from all foreign sources).

The previous discussions of parameters under "Bulk laterials Screening" adequately describe those parameters which are common to both bulk and raw materials, with the exception of "World Production Growth Rate", and "Percent From One Nation, Non-U.S.," where the raw material threshold value is different. Therefore those discussions will not be repeated here. The two parameters that change and the new U.S. and world reserve and resource parameters are discussed below.

World Production Growth Rate. The threshold value here is 7 percent rather than the 10 percent value used for bulk materials. Extractive operations usually require longer lead times and are very capital intensive. Sustained annual growth rates of 5 percent are not too unusual but 7 percent would be.

Percent From One Nation, Non-U.S. The threshold value here is 60 percent rather than the 35 percent value used for bulk materials. Developed resources tend to be more concentrated in specific locations than bulk material production facilities. However, the opportunity to exploit undeveloped resources in alternative locations generally exists. Consequently, the higher. threshold value is used.

U.S. Reserves and Resources Consumed and World Reserves and Resources Cunsumed. The Llireshold values used are 400 percent, 300 percent, 300 
percent and 200 percent, respectively. For the 50-year time span considered, those threshold values are quite conservative (see Appendix $C$ ). One could argue for many materials that they might even comfortably be doubled. In analyzing U.S. reserves and resources, sensitivity to doubling those values would be minimal, since we are usually either highly foreign source dependent - or hardly at all.

\section{Screening Process}

CMAP screening consists of comparison-of screening parameter values for each material with the parameter threshold values. CMAP asks whether or not the threshold value has been exceeded, and, if it has, sets a flag on the printout identifying the potential problem. The required logic is illustrated in Figures $A-2(1)$ (for bulk materiale) and $A-3(1)$ (for raw materials).

The results are reviewed subsequently in a manual process where materials are of ten classified as "A", "B" or "C" materials :

- "A" materials are those regarded as causing possibly serious constraints in the large scale implementation of particular designs, and thus require further study using information not stored in the data base. Mitigating strategies will likely be needed to avoid serious implementation problems.

- "B" materials are those which represent potential constraints. Thresholds are exceeded but problems do not appear severe: and/or mitigating strategies are readily identifiable. Further study may be needed to assure adequate supply.

- "C" materials are those that exceed some threshold levels, but also show by the printed data that they are not 11 kely to present a serious constraint to future deployment. 


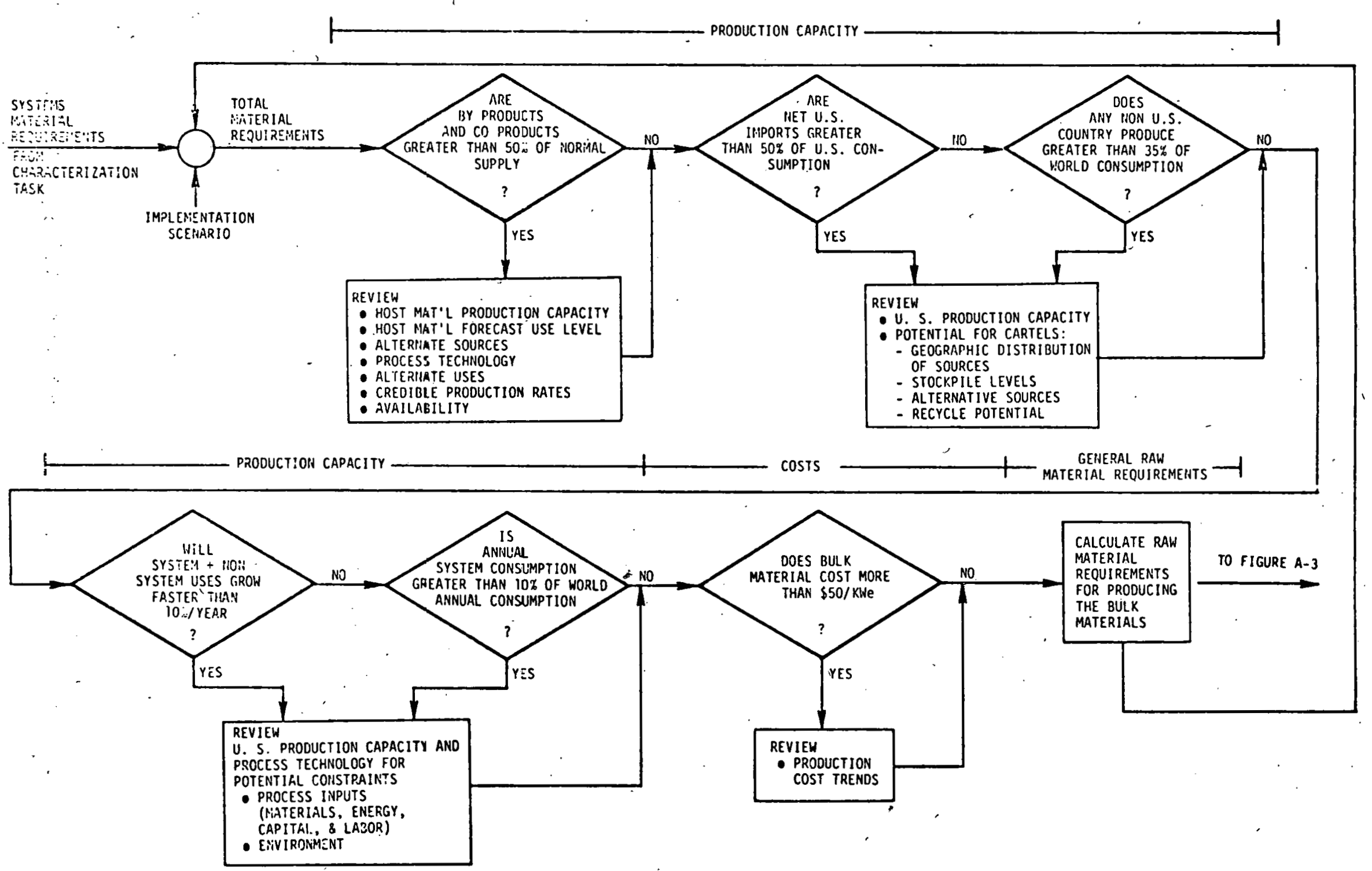

FIGURE A-2. ASSESSMENT OF POTENTIAL BULK MATERIALS PROBLEMS 


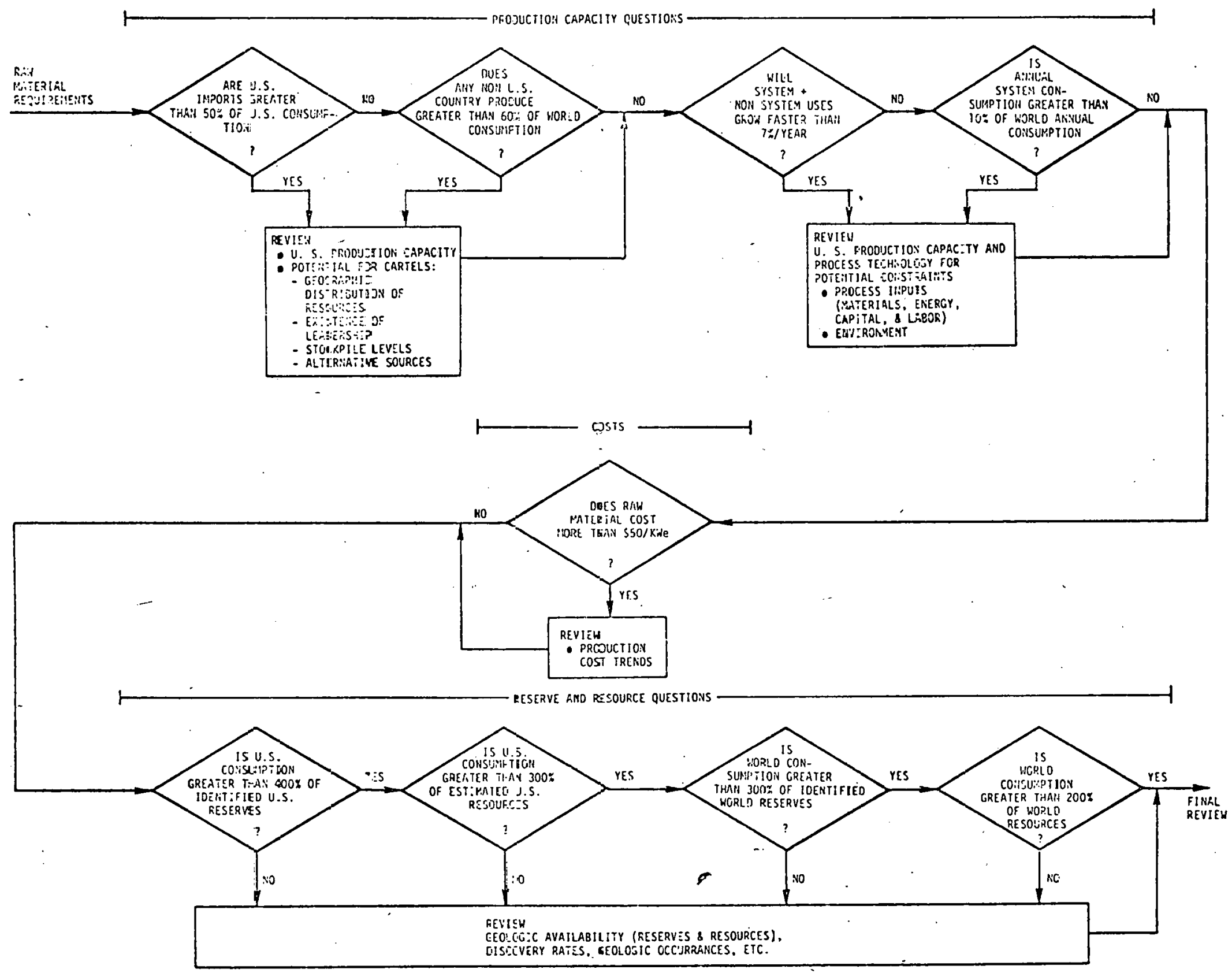

FIGIJRE A-3. ASSESSMENT OF POTENTIAL RA:N MATERIALS PROBLEMS 
APPENDIX B

SYSTEMS INCLUDED IN THE' SHACOB MATER.IALS ASSESSMENT

The following nine systems were characterized in the materials as sessment :

- Space Heating - Solaron Corporation System using $273 \mathrm{ft}^{2}$ of steel flat plate collectors - air heat transport.

- Space Heating and Domestic Hot Water - Solaron Corporation System using $273 \mathrm{ft}^{2}$ of steel flat plate collectors - air heat transport.

- Domestic Hot Water - Sunworks copper flat plate collectors .$\left(74 \mathrm{ft}^{2}\right)$ - water and ethylene glycol heat transport.

- Space Heating and Domestic Hot Water - American Heliothermal Corporation System using $268 \mathrm{ft}^{2}$ of steel flat plate collectors - water and propylene glycol heat transport.

- Space Heating and Domestic Hot Water - Ecosol Systems, Ińc., heat pump system using $258 \mathrm{ft}^{2}$ of KTA Corporation evacuated tube collectors - water heat transport.

- Space Heating and Cooling and Domestic Hot Water - Kirtland Air Force Base, Exchange Main store using absorption chillers for cooling and $8320 \mathrm{ft}^{2}$ - of Raypak, Inc., flat plate collectors with aluminum plate and copper tubing - water and ethylene glycol heat transport.

- Passive Space Heating - concrete trombe wall behind 510 $f t^{2}$ of glaring.

- Passive Space Heating - water tank trombe wall behind 510 $\mathrm{ft}^{2}$ of glazing.

- Passive Space heating - direct gain, masonry walls behind $256^{\circ} \mathrm{ft}^{2}$ of glazing.

The design variations represented by the nine systens areas follows. 
B -2

GENERALIZED DESIGN VARIATIONS OF SHACOB

Collector Number

Flat plate. 5

Evacuated tube 1

Passive

3

Heat Transfer

Air

2

Liquid

4

Application

Residential

8

Commercial

1

Energy Use

Direct

7

Heat pump

1

Absorption chiller

1 


\section{APPENDIX C}

\section{DISCUSSION OF RESERVES AND RESOURCES}

In discussing issues relative to reserves and resources it is important to understand the distinction made between these two terms. The relationship between reserves and resources is shown in the Mineral Resource Classification System developed jointly by the U.S. Geological Survey and the U.S. Bureau of Mines (see Figure C-l).

This diagram 1llustrates changing qualities of resources in terms of increasing geologic assurance and increasing economic feasibility. In this two-dimensional diagram, reserves are represented by the shaded area. In this context, reserves are defined as that portion of the resource that is located in identified deposits and can be economically extracted given current technology and mineral prices. This diagram is a static representation of a dynamic system where the quantity of reserves is continually changing due to changes in extraction and mining technology, fluctuations in market prices, and also the extent of exploration.

$y_{i}$

U.S. government estimates of available resources and reserves historically have been very conservative. For example, consider the case of bauxite (aluminum ore). Selected U.S. Bureau of Mines estimates over the 1945-1977 time span are listed below and shown graphically in Figure C-2:

$$
\begin{aligned}
& 1945-1 \times 10^{9} \text { tons } \\
& 1955-3 \times 10^{9} \\
& 1965-6 \times 10^{9} \\
& 1975-17 \times 10^{9} \\
& 1977 \quad 24 \times 10^{9}
\end{aligned}
$$

Over a 32 year time span, this represents a $2400 \%$ increase in reserve estimates.

Similarly bauxite resource estimates in 1963 and 1975 were:

$$
\begin{array}{ll}
1963 & 14.5 \times 10^{9} \text { tons } \\
1975 & 40 \times 10^{9}
\end{array}
$$

This represents over $275 \%$ increase in résource estimates over a 12-year span (see also Figure C-2). For comparison of availability with consumption, the 1975 consumption of bauxite was only $0.3 \times 10^{9}$ MT (U.S. Bureau of Mines estimate), a very small fraction of reserves and resources for what is a recyclable commodity. 


\section{TOTAL RESOURCES}

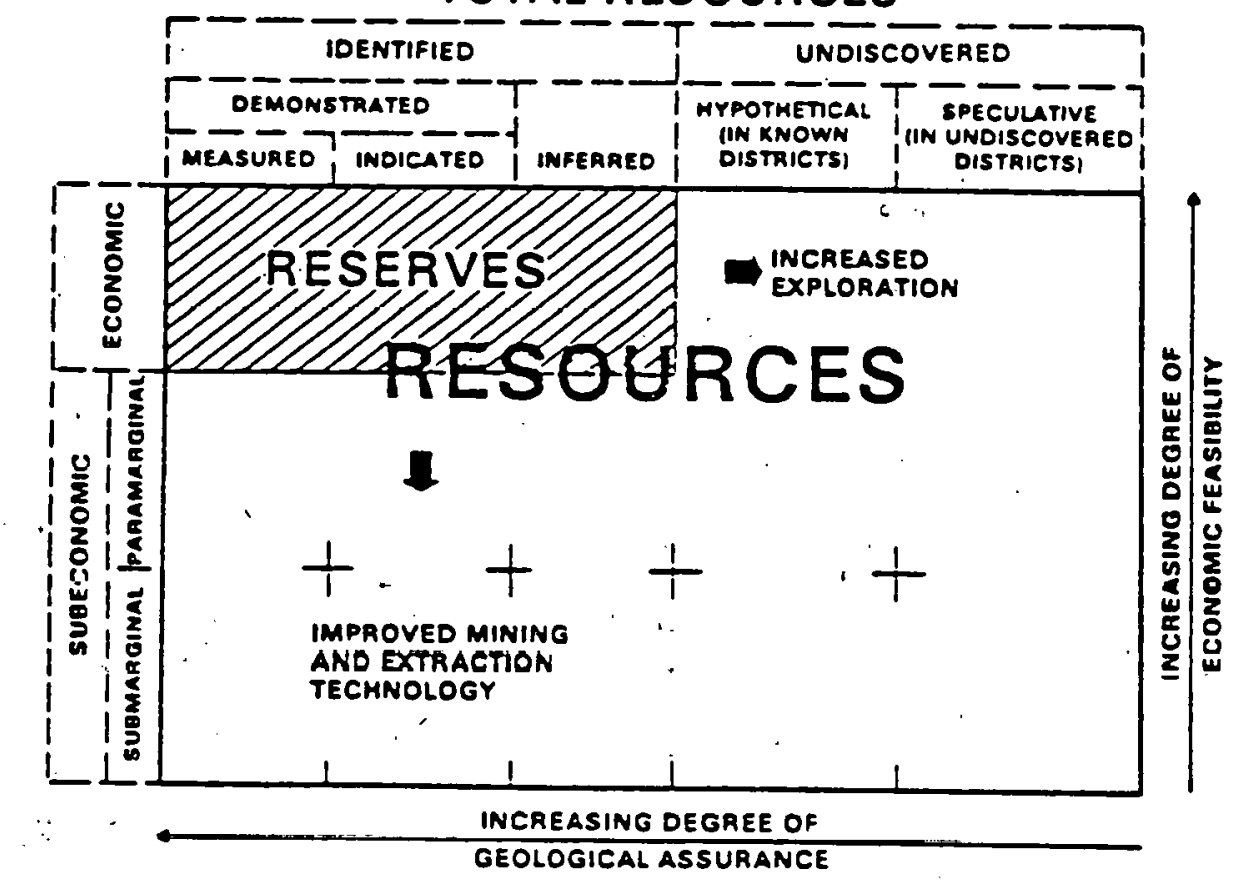

Figure C-1. CLASSIFICATION OF MINERAL" RESOURCES*

*Commodity Data Summaries 1977. Bureau of Mines, U.S. Department of Inter1or, Wash1ngton, D.C., 1977 


\section{C-3}

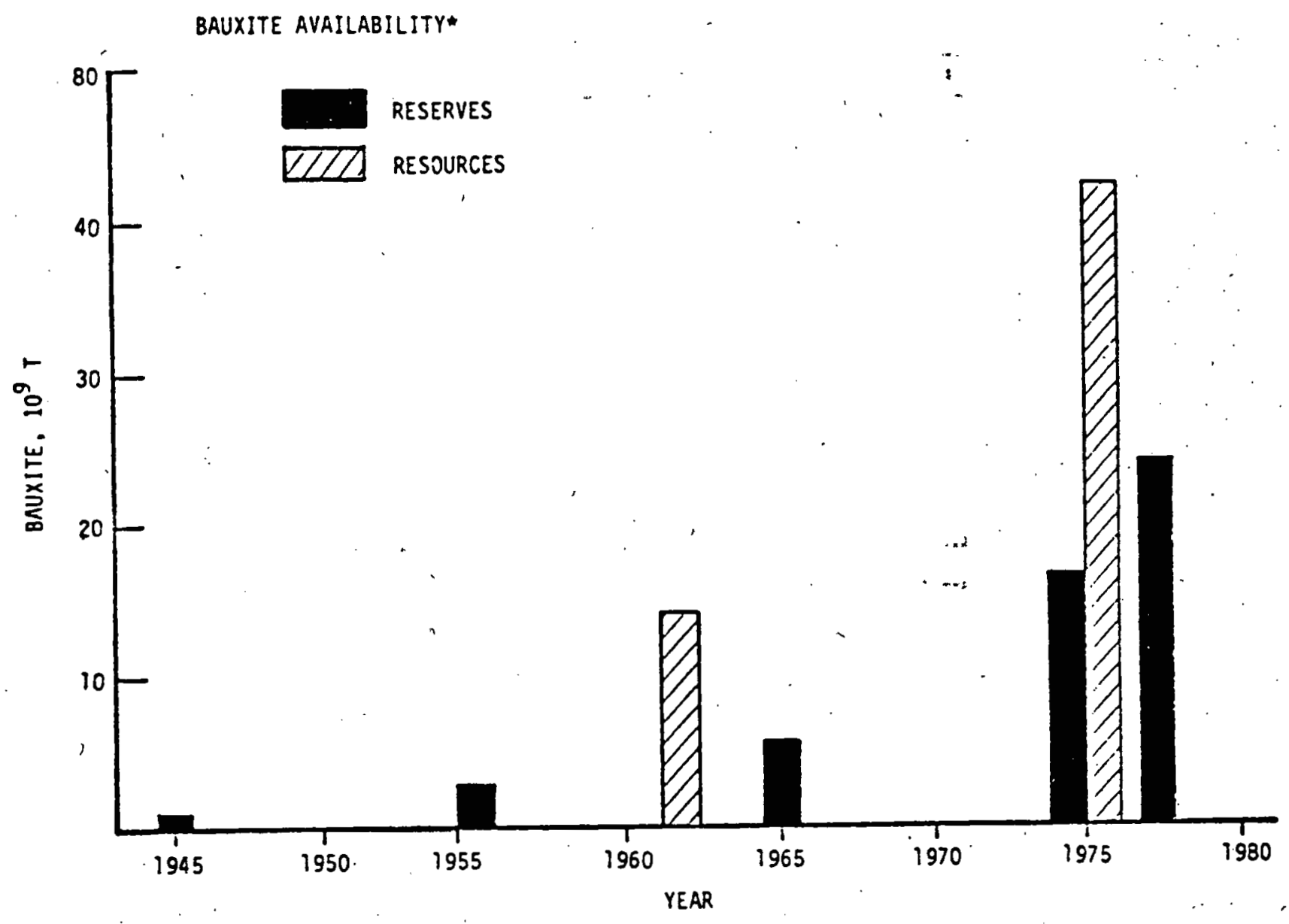

*U.S. BUREAU OF MINES

FIGURE C-2. BAUXITE AVAILABILITY*

*Commodity Data Summaries, Bureau of Mines, U.S. Department of Interior, Washington, D.C. (various years).

Mineral Facts and Problems (Bicentennial Edition), Bureau of Mines Bulletin 667, U.S. Department of Interior, Washington, D.C.; 1975. 


$$
\mathrm{C}-4
$$

These increases are due to major new discoveries, technological advances in recovery processes permitting inclusion of lower grade bauxite ores and upward movement in prices for aluminum, e.g., $\$ 0.22 / 1 \mathrm{~b}$ in current dollars in 1954 to $\$ 0.40 / 1 \mathrm{~b}$ in 1975 to $\$ 0.60+/ 1 \mathrm{~b}$ today. In constant 1973 prices, the increase is more like $10 \%$ to $15 \%$ over the 25 -year time span.

Even estimates of petroleum reserves and resources are being vastly increased under. today's new ground rules on prices. A 1978 study by the International Institute for Applied Systems Analysis in Austria estimates 2.1 trillion barrels of world oil resources recoverable at $\$ 20 /$ barrel in 1976 dollars*--a 95 year supply at present world rates of production.

Assessment of the criticality of materials.from a reserves and resources standpoint must allow for the conservative nature nf, availahflity estimates. For this reason, materials assessment threshold values for these parameters have been set at high levels: 400 percent for U.S. reserves, 300 percent for U.S. resources, 300 percent for world reserves, and 200 percent for world resources. In most cases even these values are conservative.

*Fortune, September 24, 1979, page 86. 
SOLAR SCENARIO:

INTRODUCTION YEAR- 2000

CUMULATIVE CAPACITY 2029- 295. GH

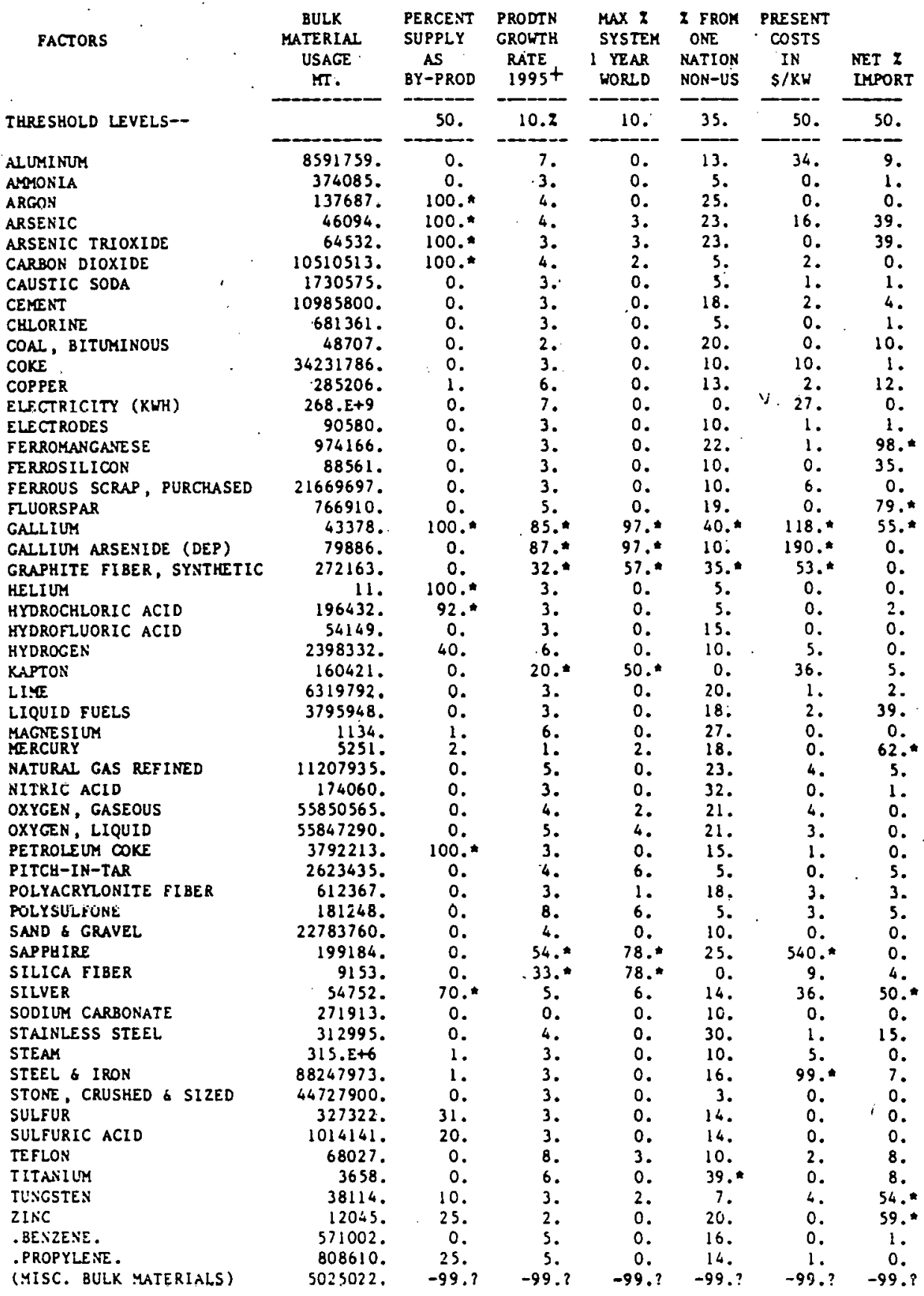

Note: + - Beginning in 1995

* Threshold exceeded

MT = Metric tons 
